\title{
Calcium Entry Related to Active Zones and Differences in Transmitter Release at Phasic and Tonic Synapses
}

\author{
M. Msghina, ${ }^{1}$ A. G. Millar, ${ }^{1}$ M. P. Charlton, ${ }^{1}$ C. K. Govind, ${ }^{2}$ and H. L. Atwood ${ }^{1}$ \\ ${ }^{1}$ Department of Physiology, Medical Research Council Neural Group, University of Toronto, Toronto, Ontario, Canada \\ M5S 1A8, and 'Life Sciences Division, University of Toronto at Scarborough, Toronto, Ontario, Canada M1C 1A4
}

Synaptic functional differentiation of crayfish phasic and tonic motor neurons is large. For one impulse, quantal release of neurotransmitter is typically $100-1000$ times higher for phasic synapses. We tested the hypothesis that differences in synaptic strength are determined by differences in synaptic calcium entry. Calcium signals were measured with the injected calcium indicator dyes Calcium Green-1 and fura-2. Estimated $\mathrm{Ca}^{2+}$ entry increased almost linearly with frequency for both axons and was two to three times larger in phasic terminals. Tonic terminal $\mathrm{Ca}^{2+}$ at $10 \mathrm{~Hz}$ exceeded phasic terminal $\mathrm{Ca}^{2+}$ at $1 \mathrm{~Hz}$, yet transmitter release was much higher for phasic terminals at these frequencies. Freeze-fracture images of synapses re- vealed on average similar numbers of prominent presynaptic active zone particles (putative ion channels) for both neurons and a two- to fourfold phasic/tonic ratio of active zones per terminal volume. This can account for the larger calcium signals seen in phasic terminals. Thus, differences in synaptic strength are less closely linked to differences in synaptic channel properties and calcium entry than to differences in calcium sensitivity of transmitter release.

Key words: crustacea; crayfish; synaptic differentiation; tonic; phasic; ultrastructure; active zone; focal recording; calcium imaging; quantal release
Synapses display a wide range of functional properties. Some show a high probability of neurotransmitter release by the nerve impulse, whereas others have a low probability of release. As yet, there is not a consensus of opinion on the important factors determining synaptic efficacy (Walmsley et al., 1998), although several mechanisms have been proposed (Parnas et al., 1982; Cooper et al., 1995a; Harris and Sultan, 1995; Dobrunz and Stevens, 1997; Murthy et al., 1997; Schikorski and Stevens, 1997). In this study, we tested one possibility: synapses that release a relatively large amount of transmitter admit more calcium than synapses that release relatively little transmitter, and the larger calcium entry accounts for the larger output of transmitter.

Motor neurons of crustaceans provide excellent models for the study of synaptic differentiation. Individual junctions of a single neuron on different target muscle fibers produce EPSPs varying greatly in amplitude and facilitation (Atwood, 1967; Bittner, 1968; Atwood and Bittner, 1971; Cooper et al., 1995a). Even greater differences in transmitter output occur at junctions of the physiologically distinct "phasic" and "tonic" motor neurons (Kennedy and Takeda, 1965a,b; Atwood, 1976; Atwood and Wojtowicz, 1986). Phasic EPSPs are usually much larger than tonic EPSPs, even in the same target muscle fiber (Bradacs et al., 1997), and

\footnotetext{
Received May 13, 1999; revised June 23, 1999; accepted July 22, 1999.

The research was supported by a Medical Research Council of Canada Group grant (Nerve Cells and Synapses) to Drs. H. L. Atwood and M. P. Charlton, by a Natural Sciences and Engineering Research Council of Canada operating grant to Dr. C. K. Govind, and by support for Dr. M. Msghina from the Faculty of Medicine, University of Toronto, and from the Swedish Medical Research Council (K97-14P11824-02B). Technical assistance was provided by Joanne Pearce and Raymond Or (for electron microscopy and freeze-fracture replicas), by Marianne HegströmWojtowicz for figure and manuscript preparation, and by Pat Quigley for assistance with data analysis.

Correspondence should be addressed to Dr. H. L. Atwood, Department of Physiology, University of Toronto, Toronto, Ontario, Canada M5S 1A8.

Dr. Msghina's present address: Department of Physiology and Pharmacology, Karolinska Institutet, S-171 77 Stockholm, Sweden.

Copyright (C) 1999 Society for Neuroscience 0270-6474/99/198419-16\$05.00/0
}

typically show depression rather than facilitation during sustained stimulation (Atwood, 1976; Lnenicka, 1991). Differences in transmitter output account for these features (Atwood and Wojtowicz, 1986). Parallel findings have been shown in amphibian and other neuromuscular junctions (Pawson and Grinnell, 1984; Wernig et al., 1984; Herrera et al., 1985; Rash et al., 1988), as well as in the central nervous systems of several species (Davis and Murphey, 1994; Stevens and Wang, 1995). Thus, patterns and principles of synaptic operation found in crustacean synapses are shared with other synapses, including mammalian central synapses.

An obvious explanation for differences in transmitter output at phasic and tonic synapses is that calcium entry is greater at phasic synapses, either because there are more calcium channels or because the calcium channels have a higher probability of opening and admit more calcium per nerve impulse. To examine this possibility, we compared the quantal release and calcium signals of phasic and tonic terminals at several frequencies of stimulation. Morphological data were obtained from images of synaptic active zones in freeze-fracture replicas. In these images, prominent membrane particles that are thought to represent the synaptic calcium channels can be seen (Pumplin et al., 1981; Walrond and Reese, 1985; Haydon et al., 1994). Our estimates of the relative effectiveness of individual active zones in admitting calcium showed that, on average, active zones of phasic synapses are not more effective than those of tonic synapses in admitting calcium during a nerve impulse. When frequency of stimulation of the tonic axon is raised to increase calcium entry, quantal output remains less, although calcium accumulation is greater, than for the phasic terminals activated at a much lower frequency. Thus, contrary to the initial hypothesis, relative calcium entry at active zones is not the main factor responsible for the large differences in transmitter release at phasic and tonic synapses.

Preliminary results have been published previously in abstract form (Msghina et al., 1995). 


\section{MATERIALS AND METHODS}

Animals and preparation. Freshwater crayfish (Procambarus clarkii; 2-4 $\mathrm{cm}$ body length) were obtained from the Atchafalaya Biological Supply Company (Baton Rouge, LA) and maintained under standard laboratory conditions (Bradacs et al., 1997). The extensor of the carpopodite (main leg extensor muscle), innervated by two excitatory motor axons, one phasic and one tonic, was selected for experimentation. The general anatomical and physiological features of the extensor muscle, and its preparation, have been described previously (Bradacs et al., 1997; Msghina and Atwood, 1997). The preparation was dissected and maintained in a modified Van Harreveld's crayfish solution containing (in mM): $\mathrm{NaCl}$ 205.3, $\mathrm{KCl} 5.3, \mathrm{CaCl}_{2} .2 \mathrm{H}_{2} \mathrm{O} 13.5, \mathrm{MgCl}_{2} \cdot 6 \mathrm{H}_{2} \mathrm{O} 2.5$, and $\mathrm{HEPES}$ buffer at $\mathrm{pH}$ 7.5). To minimize contractions, the muscle was stretched after cutting the membrane connecting the meropodite and carpopodite, leaving the tendon attachment intact. Most of the experiments were performed at room temperature $\left(19-20^{\circ} \mathrm{C}\right)$; however, focal "macropatch" recordings were performed at $13-14^{\circ} \mathrm{C}$ to aid the counting of quanta (see below). Electrophysiological recording. Properties of neurotransmitter release were assayed by extracellular recording at visualized phasic and tonic nerve endings. The procedures were similar to those described for this preparation in Msghina et al. (1998). Focal macropatch recording (Dudel, 1981; Wojtowicz et al., 1994; Cooper et al., 1995a) of the prejunctional nerve terminal spike and excitatory junction current (EJC) from single tonic and phasic terminals was performed after exposing the preparations to the vital dye 4-(4-diethylaminostyryl)- $N$-methylpyridinium iodide (4-Di-2-Asp, Molecular Probes, Eugene, OR) for 3 min at a concentration of $2 \mu \mathrm{M}$ to visualize the terminals (Cooper et al., 1995a). The macropatch electrode, pulled from Kimax glass (outer diameter, 1.5 $\mathrm{mm}$ ), was fire-polished to an internal diameter of 15-20 $\mu \mathrm{m}$, and the tip was bent to fit under a $40 \times$ Nikon water immersion objective lens (working distance, $1.0 \mathrm{~mm}$ ). The electrode, filled with the standard physiological solution, was placed under visual control over a well defined tonic terminal together with a closely adjacent phasic terminal (see Fig. $2 A$ ), so that both tonic and phasic responses were recorded from the same patch of muscle, thus circumventing the need to compensate for differences in seal or electrode resistance in comparing the responses. The patch-clamp amplifier was obtained from Zeitz-Instrument Vertriebs (Augsburg, Germany). Seal resistance was monitored throughout the recording by passing test pulses through the electrode.

The excitatory axons were stimulated by pulses delivered through a suction electrode into which the cut ends of both the tonic and phasic axons were drawn. The tonic axon, which is larger in diameter and has a lower threshold of activation (Bradacs et al., 1997), was first selectively excited by adjusting the amplitude and duration of the applied voltage, and stimulated with $500-1000$ pulses at frequencies of 1-20 Hz. After this, the stimulation intensity was increased to recruit the phasic axon, which was stimulated with 500-1000 pulses at frequencies of $1-5 \mathrm{~Hz}$. The electrophysiological data were collected and analyzed by means of a computer-based data acquisition system. The procedures for estimating quantal content of the evoked responses at different frequencies, and the fitting of the data to Poisson or binomial distributions, have been described previously (Wojtowicz et al., 1991, 1994; Cooper et al., 1995a,b; Msghina et al., 1998).

Calcium indicators and imaging. Two calcium indicators, Calcium Green-1 and fura-2, were used in the experiments to observe intracellular calcium in nerve terminals. Calcium Green- 1 was selected for its ability to produce measurable changes in calcium signal at low frequencies of stimulation (Cooper et al., 1995a), and initial experiments were performed using this indicator. The dye $(1 \mathrm{~mm}$, in $100 \mathrm{~mm} \mathrm{KCl})$, was injected into either the tonic or phasic axon with a sharp microelectrode (resistance, 50-70 $\mathrm{M} \Omega$ in $100 \mathrm{~mm} \mathrm{KCl}$ ), using a Picospritzer II pressureinjection apparatus. Continuous pressure was applied at 20-40 psi for 5-15 min. The two axons are nearly the same diameter (Bradacs et al., 1997), and when they had been injected for the same period of time with the same electrode, they had similar concentrations of the dye, as judged from fluorescence of the major axon branches. After a rest period of 30 min to allow adequate diffusion of the dye into the terminals, the preparations were stimulated for $8 \mathrm{sec}$ at each of the following frequencies: $1,2,5,10,20,30$, and $50 \mathrm{~Hz}$. The terminals were visualized using a Nikon $40 \times$ water immersion lens, and frames were captured by a confocal microscope at 1 frame/sec (see below). To ascertain that the excitatory axons were activated throughout the stimulation, the action potential was also monitored continuously.

Images for the Calcium Green-1 experiments were acquired, stored, and analyzed by a Bio-Rad 600 confocal laser scanning microscope
(Bio-Rad, Hercules, CA) and associated software. Images included the entire thickness of each sampled bouton. Calcium Green-1 fluorescence was observed during illumination by the $488 \mathrm{~nm}$ line of a $25 \mathrm{~mW}$ argon laser, attenuated to $1 \%$ of maximum with neutral density filters. Fluorescence emission was detected with a low-pass filter (cutoff at $514 \mathrm{~nm}$ ). Background fluorescence was subtracted from resting and stimulationinduced fluorescence intensity values. At each frequency, the resting fluorescence value was subtracted from the stimulation-induced value, and the result $(\Delta F)$ was normalized to the resting fluorescence intensity $(F)$ to give $\Delta F / F$.

During stimulation, the normalized fluorescence values for Calcium Green-1 $(\Delta F / F)$ provided the initial measure of calcium change in the terminals. The dependence of these values on intraterminal calcium concentration was determined by measuring the fluorescence in calibration solutions with known $\left[\mathrm{Ca}^{2+}\right]$ (Fig. 1). These solutions, obtained from Molecular Probes (Calcium Indicator Calibration Kit) were imaged in $50 \mu \mathrm{m}$ cuvettes (Vitro Dynamics, Rockaway, NJ) to determine how close experimentally predicted concentrations were to actual values. First, $F_{\max }$ (fluorescence intensity at saturating $\left[\mathrm{Ca}^{2+}\right]$ ) and $F_{\text {min }}$ (fluorescence intensity at zero $\left[\mathrm{Ca}^{2+}\right]$ ) were determined in vitro for the selected dye concentration $\left(10 \mu \mathrm{M}\right.$ Calcium Green-1). The $K_{\mathrm{d}}$ value for Calcium Green-1 was estimated to be $138 \mathrm{~nm}$, from the linear plot of $\log \left(F-F_{\min }\right) /\left(F_{\max }-F\right)$ against $\log \left[\mathrm{Ca}^{2+}\right]$ (Fig. $\left.1 A\right)$. Next, new solutions with varying levels of $\mathrm{Ca}^{2+}$ and the same dye concentration were imaged, and the fluorescence intensity was recorded. Measured fluorescence values were inserted into the equation $\left[\mathrm{Ca}^{2+}\right]=K_{\mathrm{d}}\left(F-F_{\min }\right) / F_{\text {max }}$ $-F$ ) to obtain predicted $\left[\mathrm{Ca}^{2+}\right]$ concentrations for a given fluorescence intensity. The predicted concentrations were then compared with the "actual" concentration of the calibration solution reported by Molecular Probes. The fluorescence of Calcium Green-1 accurately predicted calcium concentrations to $\pm 10 \%$ if the dye concentration was kept constant (Fig. 1C). When $\Delta F / F_{\min }$ was plotted against $\log \left[\mathrm{Ca}^{2+}\right]$, the relationship was linear over the range $2 \times 10^{-8}$ to $10^{-6} \mathrm{M}$ (Fig. $1 \mathrm{~B}$ ); at higher concentrations, the slope of the curve decreased and thus the readings above $10^{-6} \mathrm{M}$ were less accurate. From these calibrations, and with the resting values of $\mathrm{Ca}^{2+}$ determined from fura- 2 measurements, the change in fluorescence of Calcium Green- 1 was used as a measure of the change in $\left[\mathrm{Ca}^{2+}\right]$ when the latter value was below $10^{-6} \mathrm{M}$.

Measurements of resting and stimulus-evoked $\left[\mathrm{Ca}^{2+}\right]$ were also made with the ratiometric calcium indicator fura-2. Estimation of $\left[\mathrm{Ca}^{2+}\right]_{i}$ was more direct using the ratiometric dye, and the kinetics of rise and decay of $\left[\mathrm{Ca}^{2+}\right]_{\mathrm{i}}$ could be better resolved because of the imaging system's higher acquisition rate. However, changes in $\left[\mathrm{Ca}^{2+}\right]$ at low frequencies of stimulation were less easily detected than with Calcium Green-1. The procedures for using fura-2 in crayfish axons and for calibrating it for intraterminal $\mathrm{Ca}^{2+}\left(\left[\mathrm{Ca}^{2+}\right]_{i}\right)$ have been described thoroughly in several previous publications (Delaney et al., 1989; Delaney and Tank, 1994; Tank et al., 1995; Ravin et al., 1997). In general, the procedures used in the present study were similar to those given by Delaney et al. (1989) and Ravin et al. (1997). In brief, fura-2 pentapotassium salt (Molecular Probes) was diluted to $20 \mathrm{~mm}$ in a solution containing $100 \mathrm{~mm} \mathrm{KCl}$ and $20 \mathrm{~mm}$ HEPES, $\mathrm{pH}$ 7.4. The tonic or phasic axon was penetrated with a single-barrel thick-walled glass microelectrode (20-40 $\mathrm{M} \Omega$ when filled with $3 \mathrm{M} \mathrm{KCl}$ ) containing the fura- 2 dye solution. The neurons were filled iontophoretically by passing 10-15 nA negative DC current for 10-15 $\mathrm{min}$. The fura-2 was allowed to diff use fully into the nerve terminals for $30 \mathrm{~min}$ after injection. After this diffusion period, when stable dye fluorescence was observed in boutons close to the injection site, nerve terminals were readily imaged within $1-2 \mathrm{~mm}$ of the injection site. Axons were stimulated selectively by varying the voltage applied through a suction electrode in which they had been placed. The phasic or tonic axon was stimulated with a brief train, $10 \mathrm{sec}$ in duration, at 2, 5, 10, 20, 30, 40, or $50 \mathrm{~Hz}$ (tonic axons received additional trains at frequencies of 75,100 , and $200 \mathrm{~Hz}$ ), followed by a $1 \mathrm{~min}$ rest period.

$\left[\mathrm{Ca}^{2+}\right]$ was determined ratiometrically from a standard imaging system fitted with bandpass excitation filters of $360 \pm 10$ and $385 \pm 5 \mathrm{~nm}$ in a filter wheel, and a $530 \pm 35 \mathrm{~nm}$ bandpass emission filter (Omega Filters). The terminals were visualized using an Olympus $40 \times$ water immersion objective, and frames were captured using an intensified CCD camera (IC-100, PTI) at four frames/sec, using AIW 2.1 (Axon Instruments, Foster City, CA).

Images were acquired by briefly exposing ( $33 \mathrm{msec}$ per image) the preparation to excitation wavelengths of 360 and $385 \mathrm{~nm}$. One image was acquired at $360 \mathrm{~nm}$ (the isobestic point of fura-2) followed by successive images at $385 \mathrm{~nm}$. The $360 \mathrm{~nm}$ image was divided by successive $385 \mathrm{~nm}$ 

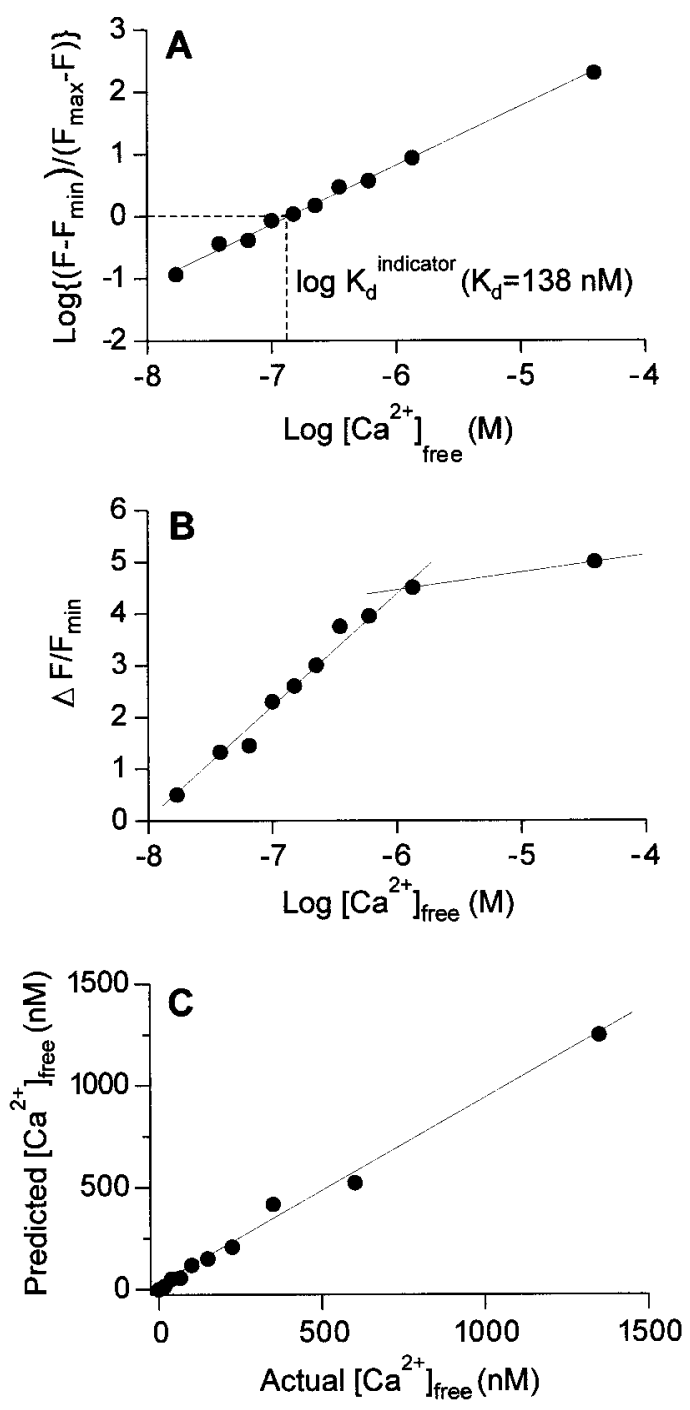

Figure 1. Calibration curves for Calcium Green-1. A, Relationship between fluorescence measurements and free calcium, with an estimate of $K_{\mathrm{d}} . B$, Relationship between normalized fluorescence change and free calcium, showing a linear relationship between normalized fluorescence and $\log \left[\mathrm{Ca}^{2+}\right]$ between $10^{-8}$ and $10^{-6} \mathrm{M}\left[\mathrm{Ca}^{2+}\right]$. $C$, Predictive value of Calcium Green-1. Using predetermined values for $R_{\max }, R_{\min }$, and $K_{\mathrm{d}}$, Calcium Green-1 fluorescence values $(F)$ from several calibration solutions (Molecular Probes Calcium Imaging Calibration Kit) were substituted into the equation $\left[\mathrm{Ca}^{2+}\right]=K_{\mathrm{d}}\left(F-F_{\min } / F_{\max }-F\right)$. The predicted value of $\left[\mathrm{Ca}^{2+}\right]$ given by the equation is plotted against the actual value reported by Molecular Probes. The shape of this relationship is linear, with a slope of $\sim 1$, indicating that Calcium Green- 1 accurately predicts $\left[\mathrm{Ca}^{2+}\right]$ in the range plotted. $F$, Fluorescence at $\times\left[\mathrm{Ca}^{2+}\right]_{\text {free }} ; F_{\max }$, fluorescence at saturating $\left[\mathrm{Ca}^{2+}\right]_{\text {free }} ; F_{\min }$, fluorescence at $0\left[\mathrm{Ca}^{2+}\right]_{\text {free }}$, $\Delta F=F-F_{\min }$.

images (pixel by pixel), thus creating a series of ratio images. Background fluorescence was determined from a region of muscle near the nerve terminals that were imaged and was subtracted from both 360 and $385 \mathrm{~nm}$ images before ratios were calculated. As noted previously in Delaney et al. (1989), autofluorescence of the exoskeleton was appreciable; therefore terminals were imaged from areas with relatively low background fluorescence. For determination of resting $\left[\mathrm{Ca}^{2+}\right]$, individual terminals were selected, and the mean ratio for each specified terminal was determined. Ratios were then averaged over a $5 \mathrm{sec}$ acquisition period. Resting and stimulus-evoked ratios for each nerve terminal were converted into an absolute calcium concentration using Equation 5 of Grynkiewicz et al. (1985).

Fura-2 ratiometric data were calibrated in vitro using a commercially available kit (Molecular Probes fura-2 Calcium Imaging Calibration Kit). Solutions containing $50 \mu \mathrm{M}$ fura-2, $100 \mathrm{~mm} \mathrm{KCl}$, and defined $\left[\mathrm{Ca}^{2+}\right]$ ranging from 0 to $39 \mu \mathrm{M}$ were imaged in $50 \mu \mathrm{m}$ quartz capillary tubes (Vitro Dynamics). Ratios for zero $\left[\mathrm{Ca}^{2+}\right]\left(R_{\min }\right)$ and saturating $\left[\mathrm{Ca}^{2+}\right]\left(R_{\max }\right)$ were determined after background fluorescence from a fura-2-free solution had been subtracted. A viscosity correction factor of 0.7 was applied to $R_{\max }$ and $R_{\min }$ (Delaney et al., 1989; Poenie, 1990). To further verify the results of the in vitro calibration, an in vivo calibration was also performed, generally following the procedure found in Ravin et al., (1997). $R_{\min }$ was determined in fura-2-loaded terminals after the preparation was incubated in calcium-free Van Harreveld's solution with $2 \mathrm{~mm}$ EGTA and $10 \mu \mathrm{M}$ ionomycin for $1 \mathrm{hr}$. The ratio decreased slowly and was stable after $1 \mathrm{hr}$, at which point $R_{\min }$ was measured. To establish $R_{\max }$, the bathing solution was changed to Van Harreveld's solution containing $50 \mu \mathrm{M}$ carbonyl cyanide $m$-chlorophenyl hydrazone to release $\left[\mathrm{Ca}^{2+}\right]$ from mitochondria, and $10 \mu \mathrm{M}$ ionomycin. The ratio increased rapidly and reached a maximum in $<5 \mathrm{~min}$, after which $R_{\max }$ was measured. Calibration values obtained from the in vivo procedure were similar to those obtained from viscosity-corrected in vitro calibrations. The values of $R_{\min }$ and $R_{\max }$ were substituted into Equation 5 of Grynkiewicz et al. (1985), along with the value $S_{\mathrm{f}} / S_{\mathrm{b}}$ (zero calcium fluorescence at $385 \mathrm{~nm}$ divided by saturating calcium fluorescence at $385 \mathrm{~nm}$ ) and $K_{\mathrm{d}}$ of the fura-2 in crayfish nerve terminals [ $865 \mathrm{~nm}$ according to Delaney et al. (1991)].

To reduce twitching of the muscle at high stimulation frequencies, a glutamate receptor blocker, Jorotoxin (JSTX, Calbiochem, La Jolla, CA), was applied to the preparation at a concentration of $50 \mu \mathrm{M}$ diluted in Van Harreveld's solution for 15 min (Quigley and Mercier, 1997). This effectively blocked contraction of the muscle, whereas it left presynaptic calcium signals unaltered.

Ultrastructural analysis. For transmission electron microscopy, samples of axons and neuromuscular junctions were obtained using standard fixation, embedding, and sectioning procedures (Jahromi and Atwood, 1974; King et al., 1996). Procedures for electron microscopy of freeze-fracture replicas were similar to those used previously for other crustacean neuromuscular preparations (Pearce et al., 1986; Walrond et al., 1993; Govind et al., 1994, 1995).

\section{RESULTS}

\section{Quantal release from visualized tonic and phasic terminals}

Differences in transmitter release were shown by comparing synaptic currents at small, well defined regions of the nerve terminal. We compared neurotransmitter release at recording sites where phasic and tonic terminals were close together on the same muscle fiber and could be assayed with a single placement of the recording electrode (Msghina et al., 1998). A focal macropatch electrode (15-20 $\mu \mathrm{m})$ was placed under visual control over a single prominent tonic bouton and adjacent phasic terminals (Fig. 2A) to record the presynaptic nerve terminal spike together with spontaneous and evoked tonic and phasic quantal events (Fig. 2B,C) from the same patch. The tonic axon was first selectively stimulated at 1-20 Hz, providing data on evoked quantal release (Fig. $2 B, D)$. At stimulation frequencies below $5 \mathrm{~Hz}$, tonic terminals released very few quanta. When quantal events occurred, they were mostly single events and similar in size to spontaneously occurring EJCs, which were taken to represent single quantal events (Fig. 2B). The small numbers of evoked quantal events made it feasible to count the number of quantal units evoked by each impulse of the series (Cooper et al., 1995b).

When the phasic axon was recruited, a markedly different result was obtained. All impulses of a series released multiple quantal units and frequently "late events" in the form of individual quantal units (Fig. 2C). At $1 \mathrm{~Hz}$, phasic EJCs were up to 18 times the amplitude of individual quantal events, indicating a large quantal content at low frequencies of activation (Fig. 2C,D). Generally, transmitter release declined slowly during maintained stimulation at $1 \mathrm{~Hz}$ (Fig. 2D). For comparison, recordings were 
A
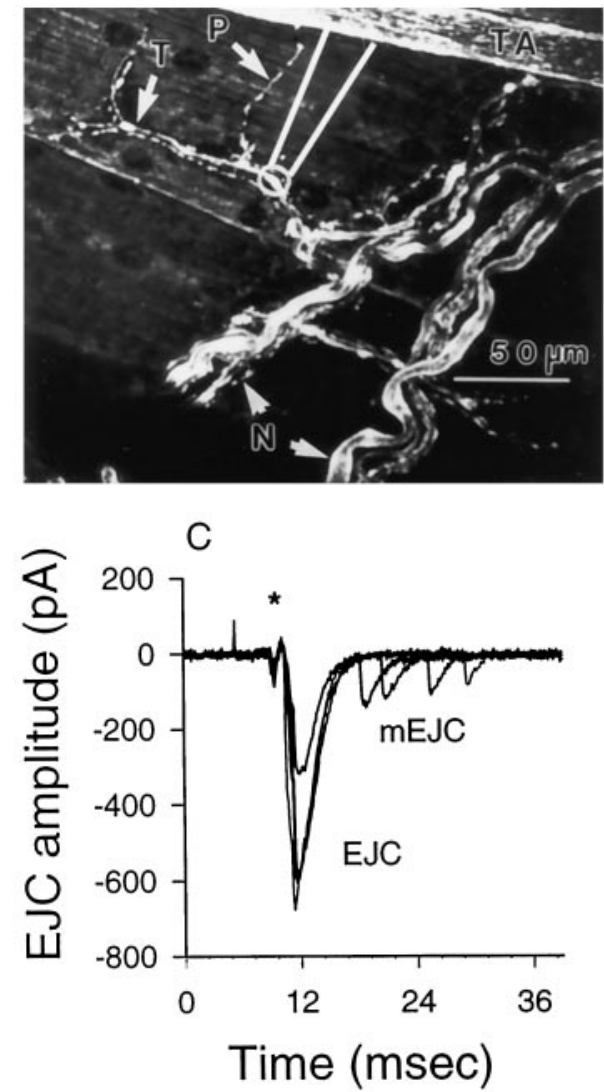

B

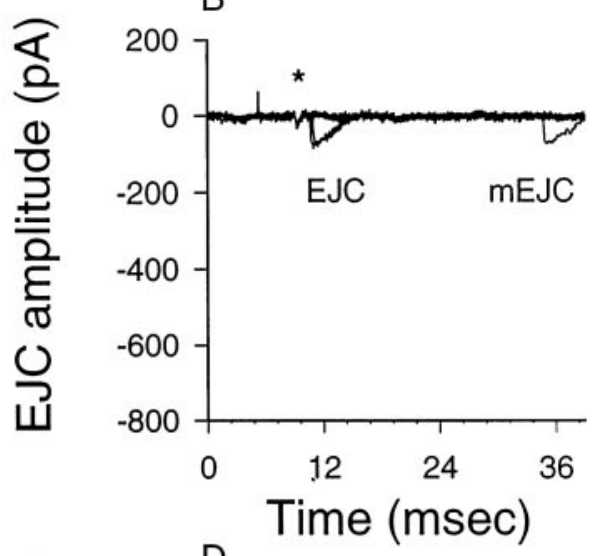

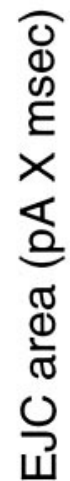

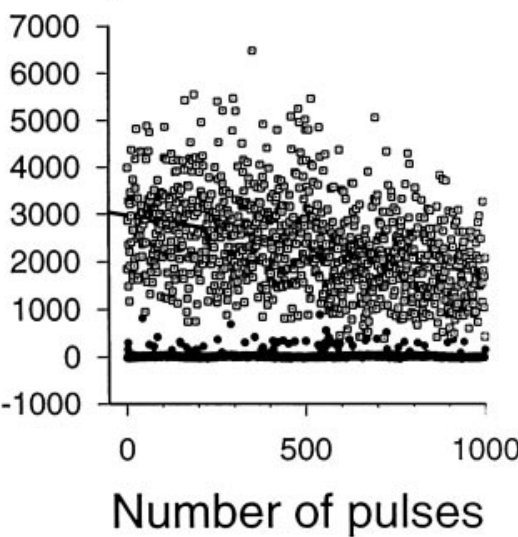

Figure 2. Focal recordings of synaptic currents from phasic and tonic nerve terminals at $1 \mathrm{~Hz}$. A, Recording location for conjoint assay of phasic and tonic transmission on a single muscle fiber. Phasic $(P)$ and tonic $(T)$ nerve terminals were vitally stained with 4-Di-2-Asp and visualized under the confocal microscope. A major secondary nerve branch $(N)$ containing the two motor axons crosses the muscle fibers transversely, giving off smaller tertiary synapse-bearing branches from which recordings were made. A recording site for the "macropatch" electrode, connected to the recording preamplifier, is diagrammed. The primary tonic axon $(T A), \sim 25 \mu \mathrm{m}$ in diameter, appears in the top right-hand corner. B, $C$, Focal recordings made sequentially from tonic and phasic terminals at a single site. The tonic and phasic primary axons were stimulated at $1 \mathrm{~Hz}$. Extracellular nerve terminal spikes are indicated by asterisks. $B$, Eight superimposed records of selected responses to stimulation of the tonic axon; two evoked excitatory junctional currents $(E J C \mathrm{~s})$ and one "late release" or miniature excitatory junctional current $(m E J C)$ appeared. The majority of stimuli evoked no response at this frequency. $C$, Four superimposed records of selected responses at the same site to stimulation of the phasic axon. Four late releases $(m E J C s)$ are shown. All stimuli evoked multi-quantal EJCs. $D$, Plot of EJCs (current-time integrals) produced by phasic $(\square)$ and tonic $(\bullet)$ nerve terminals in response to 1000 stimuli at the site recorded from in $B$ and $C$. EJC measurements are plotted against sweep number. Numerous failures of release occur in the tonic response; none occur in the phasic response. Gradual depression is evident over time in the phasic responses and is indicated by a regression line.

also made from isolated phasic terminals unaccompanied by a tonic terminal; the general result was the same.

Estimates of quantal content at $1 \mathrm{~Hz}$ for paired phasic and tonic terminals were made in several experiments to compare the effectiveness of single nerve impulses in releasing quantal units. For the tonic terminals, all quantal units that were released could be accurately counted. For the phasic terminals, many quantal units were released per impulse, and accurate counts of the number of individual quantal events could not be made. Estimates of mean quantal content for phasic terminals were derived by dividing the mean evoked response by the mean quantal unit amplitude. An additional measure of relative output at the same site was provided by averaging the evoked EJCs and comparing their amplitude-time integrals (Cooper et al., 1995b; Msghina et al., 1998). As illustrated in Figures $2 D$ and $3 B, D$, these estimates always showed a large difference in quantal release for phasic and tonic terminals at the same recording sites. Phasic/tonic ratios of the quantal content at $1 \mathrm{~Hz}$ ranged from 94 to 1300 in seven experiments, with a mean value of 208 (Table 1).
Short-term facilitation (frequency facilitation) of transmitter release was also compared for the two terminals using the steadystate EJC attained during brief trains as a measure of facilitation. During repetitive stimulation at different frequencies ranging from 1 to $20 \mathrm{~Hz}$, there was a very large facilitation of transmitter release from tonic terminals (Fig. $3 A, B$ ). From 1 to $20 \mathrm{~Hz}$, quantal content increased by up to 100 -fold, and many stimuli now caused the release of two to four quanta at $20 \mathrm{~Hz}$. Phasic terminals, on the other hand, showed much less facilitation when tested at $1-5 \mathrm{~Hz}$ (Fig. 3C,D). At frequencies $>5 \mathrm{~Hz}$, the signals at phasic terminals were often contaminated by events at nearby synapses outside the lumen of the recording electrode, which resulted in a mixture of positive- and negative-going signals. These contaminating signals have previously been described and analyzed in detail at crayfish synapses by Dudel (1965) and Ortiz (1972). In addition, muscle movement was a significant problem at the higher frequencies. Therefore, phasic events were not studied in detail at frequencies higher than $5 \mathrm{~Hz}$. The ratio of transmitter release at 5 and $1 \mathrm{~Hz}$ for phasic terminals was always $<2$ (Fig. 

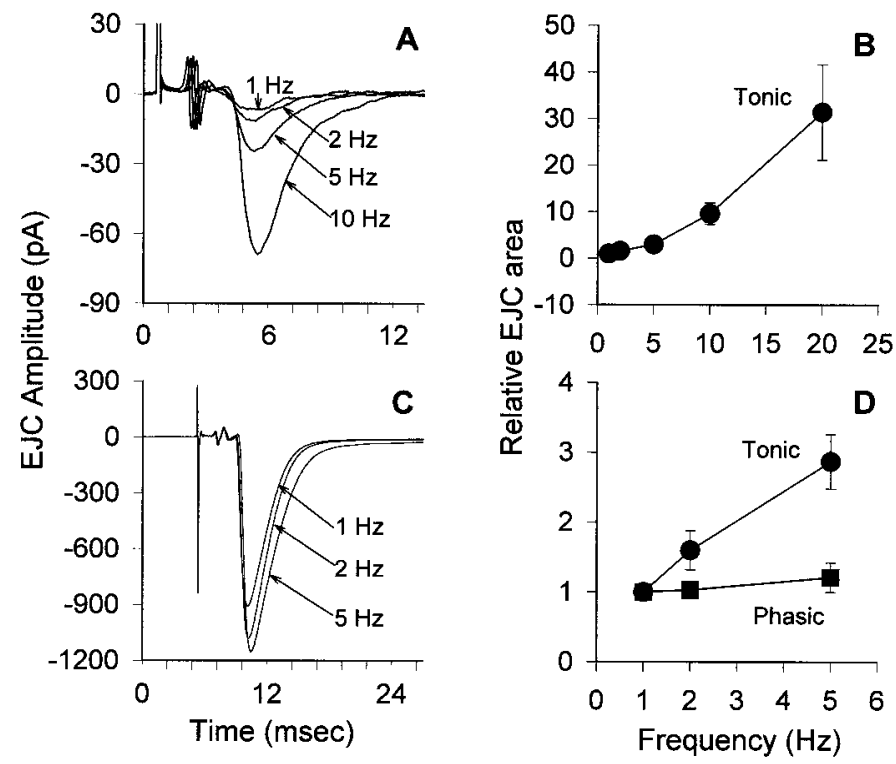

Figure 3. Frequency facilitation at tonic $(A, B)$ and phasic $(C, D)$ nerve terminals. $A$, Averaged records of EJCs from a tonic terminal at four different frequencies $(1,2,5,10 \mathrm{~Hz})$. In each case, 500 responses were averaged. Extracellular nerve terminal spikes are indicated by the asterisks. $B$, Graph of relative changes in the averaged EJC (current-time area measurements) over the frequency range of $1-20 \mathrm{~Hz}$. $C$, Averaged records of EJCs from a phasic terminal at three different frequencies $(1,2,5 \mathrm{~Hz}$; 500 responses for each frequency). D, Graph of relative changes in the averaged EJC for the phasic terminal (ם) and the tonic terminal (ט) over the range of $1-5 \mathrm{~Hz}$; measurements were normalized to the values at $1 \mathrm{~Hz}$ to make the phasic-tonic comparison. A marked difference in frequency facilitation is apparent.

Table 1. Quantal contents for paired phasic and tonic terminals at 1 Hz stimulation

\begin{tabular}{lclc} 
Experiment & Phasic & Tonic & $\begin{array}{l}\text { Ratio: } \\
\text { phasic/tonic }\end{array}$ \\
\hline 1 & 9.78 & 0.059 & 165.9 \\
2 & 11.26 & 0.065 & 173 \\
3 & 11.8 & 0.02 & 590 \\
4 & 3.43 & 0.024 & 142.9 \\
5 & 7.0 & 0.024 & 292 \\
6 & 18.0 & 0.192 & 94 \\
7 & 5.2 & 0.004 & 1300 \\
Mean \pm SEM & $9.5 \pm 1.84$ & $0.055 \pm 0.0242$ & $208.4 \pm 71.7$
\end{tabular}

$\overline{\text { Data for experiments 5, 6, and } 7 \text { are taken from experiments reported in Msghina et }}$ al. (1998).

$3 C, D)$, whereas for tonic terminals, the ratios were always $>2$ (Fig. $3 D$ ).

Even with the pronounced frequency facilitation, tonic terminals still released less transmitter at frequencies of 10 and $20 \mathrm{~Hz}$ than did phasic terminals at $1 \mathrm{~Hz}$. The mean quantal content for phasic terminals at $1 \mathrm{~Hz}$ was 9.5 (Table 1 ). Tonic terminals facilitated tenfold at $10 \mathrm{~Hz}$ (Fig. 3B). Thus, the value found at 1 $\mathrm{Hz}(0.055$, Table 1$)$ would rise to a mean quantal content of $\sim 0.5$ at $10 \mathrm{~Hz}$. This value is much lower than that for phasic terminals at $1 \mathrm{~Hz}$. This large difference in release can be compared with the relative calcium signals of the two terminals when considering the importance of calcium entry for determination of synaptic strength in the two axons.

\section{Calcium responses in tonic and phasic terminals}

Calcium entry to the active zones of synapses is believed to be the trigger for evoked release of transmitter (for review, see Augustine and Charlton, 1986; Llinas et al., 1992; Zucker, 1996; Stanley, 1997), and one possible reason for the difference in synaptic strength of phasic and tonic axons is that there is more calcium entry at synapses of phasic terminals. If there is a third- to fourth-power relationship between calcium entry at the synapse and immediate transmitter release, as has been proposed in previous studies (Zucker and Lara-Estrella, 1983; Augustine and Charlton, 1986; Zucker, 1996), a 200-fold difference in quantal release at $1 \mathrm{~Hz}$ (Table 1) would imply a five- to sixfold greater calcium entry per synapse in phasic terminals. To test this hypothesis, we estimated the relative calcium entry and then compared this with the estimated number of synapses and putative synaptic calcium channels from ultrastructural studies. The combined physiological and ultrastructural data were used to compare the average calcium entry per synapse for the two terminals at low frequencies of activation and to assess the likelihood that $\mathrm{Ca}$ channels of phasic terminals are more effective in admitting $\mathrm{Ca}^{2+}$.

Intraterminal calcium accumulating during impulse activity can be estimated using calcium indicators injected into the motor axon's preterminal branches (Delaney et al., 1989; Cooper et al., 1995a). The calcium so measured can be described by a singlecompartment model in which $\left[\mathrm{Ca}^{2+}\right]_{\mathrm{i}}$ has reached equilibrium throughout the terminal $<100 \mathrm{msec}$ after entry at synapses, and in which influx and efflux are in equilibrium during a train of stimuli (Tank et al., 1995). A linear relationship between $\left[\mathrm{Ca}^{2+}\right]_{\mathrm{i}}$ and stimulation frequency is an outcome of this model. The single-compartment model provides a good theoretical basis for comparing the calcium signals in the two terminals during short trains of impulses.

Observations of $\left[\mathrm{Ca}^{2+}\right]_{\mathrm{i}}$ during stimulation were initially made with Calcium Green-1, which gives easily detectable signals at low frequencies (Cooper et al., 1995a). Subsequent measurements were made with fura-2, which allows $\left[\mathrm{Ca}^{2+}\right]_{\mathrm{i}}$ to be estimated ratiometrically. Resting levels of $\left[\mathrm{Ca}^{2+}\right]_{i}$ as well as stimulusevoked $\left[\mathrm{Ca}^{2+}\right]_{\mathrm{i}}$ were estimated with fura- 2 .

Values for the resting levels of $\left[\mathrm{Ca}^{2+}\right]_{i}$ were made by ratiometric imaging of individual boutons (synapse-bearing varicosities) and axon branches in several preparations. Phasic and tonic terminals were easy to distinguish because they differ greatly in morphology (Fig. 2A) (Bradacs et al., 1997). The mean values $( \pm$ SEM $)$ for resting $\left[\mathrm{Ca}^{2+}\right]_{\mathrm{i}}$ were $145 \pm 4.5 \mathrm{nM}(n=91,5$ specimens) for tonic boutons and $207 \pm 8.5 \mathrm{nM}(n=71,3$ specimens) for phasic boutons; the means were significantly different statistically $(p \leq 0.01)$. These values were used for estimating changes in calcium during impulse activity from fluorescence changes of Calcium Green-1.

Two sets of observations of calcium signals during impulse activity were made on nerve terminals injected with the two different calcium indicators, Calcium Green-1 and fura-2. For the Calcium Green-1 images, the motor axons were successively stimulated for $8 \mathrm{sec}$ periods at progressively higher frequencies over the range of $1-50 \mathrm{~Hz}$. These short stimulation periods were sufficient for $\left[\mathrm{Ca}^{2+}\right]_{\mathrm{i}}$ to attain a steady level but not long enough to produce complications caused by delayed leakage of $\mathrm{Ca}^{2+}$ from mitochondria after stimulation at low frequencies (Tang and Zucker, 1997).

In tonic terminals, a small calcium signal $(\Delta F / F)$ was detected at stimulation frequencies below $2 \mathrm{~Hz}$, and as the frequency was 


\section{Calcium Green-1 imaging}
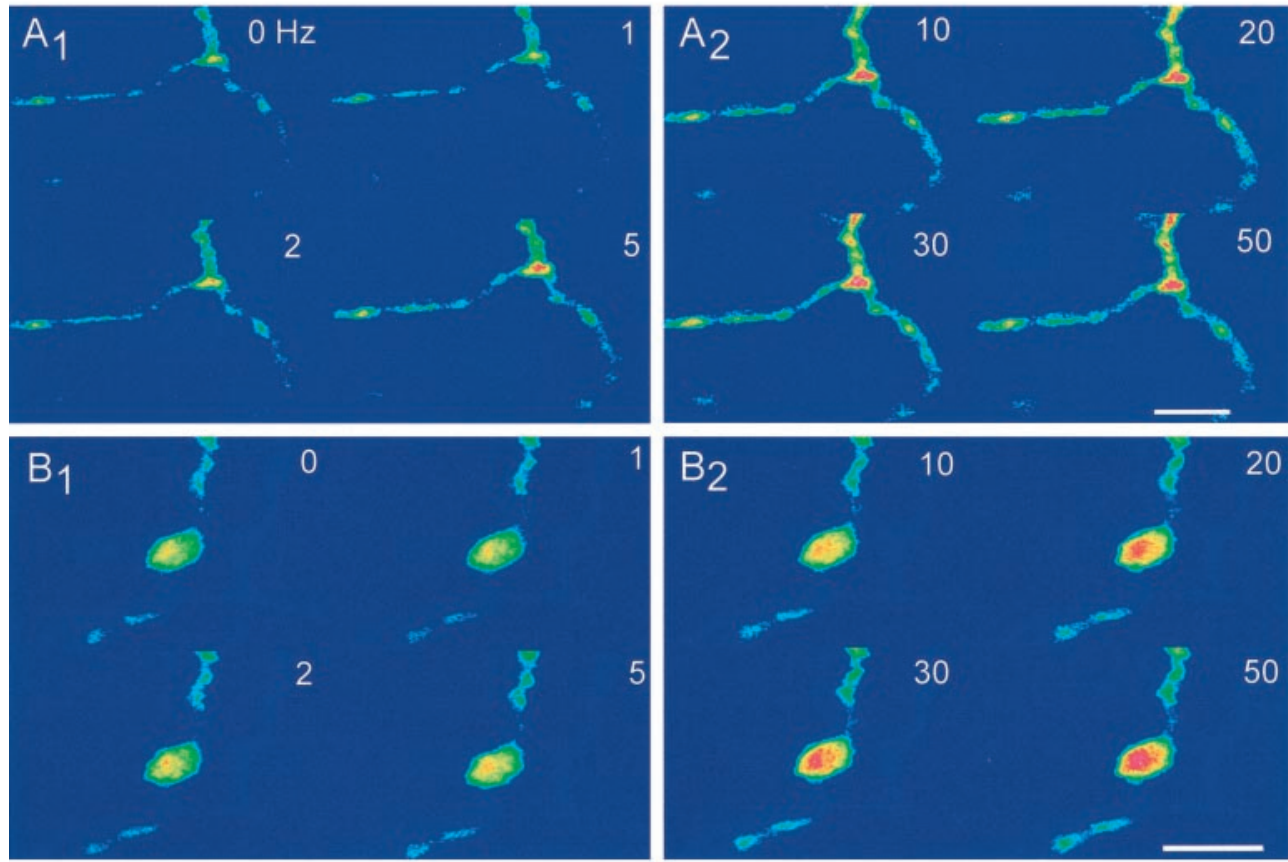

Figure 4. Calcium imaging of phasic and tonic terminals showing examples for Calcium Green-1 (I, top panels) and fura-2 (II, bottom panels). I. Calcium Green-1 imaging, The preparations were stimulated for $8 \mathrm{sec}$ periods at frequencies ranging from 1 to $50 \mathrm{~Hz}$. $A$, Phasic terminals; $B$, tonic terminals. In both cases, the first image, labeled 0 , represents the control (unstimulated) condition. Frequencies $(\mathrm{Hz})$ are indicated for each image. Scale bar, $12.5 \mu \mathrm{m}$. II. Fura-2 imaging, Calibrated ratio images are shown. The preparations were stimulated for $10 \mathrm{sec}$ periods at frequencies ranging from 2 to 40 $\mathrm{Hz}$, followed by a rest period of $1 \mathrm{~min}$ after each period of stimulation. $A$, Phasic terminals; $B$, tonic terminals. Frequencies $(\mathrm{Hz})$ are indicated for each image. Phasic terminals show more $\mathrm{Ca}^{2+}$ accumulation at a given frequency. Intraterminal $\left[\mathrm{Ca}^{2+}\right]$ can be estimated by using the calibrated color bar. Scale bar, $10.0 \mu \mathrm{m}$.

\section{Fura-2 imaging}
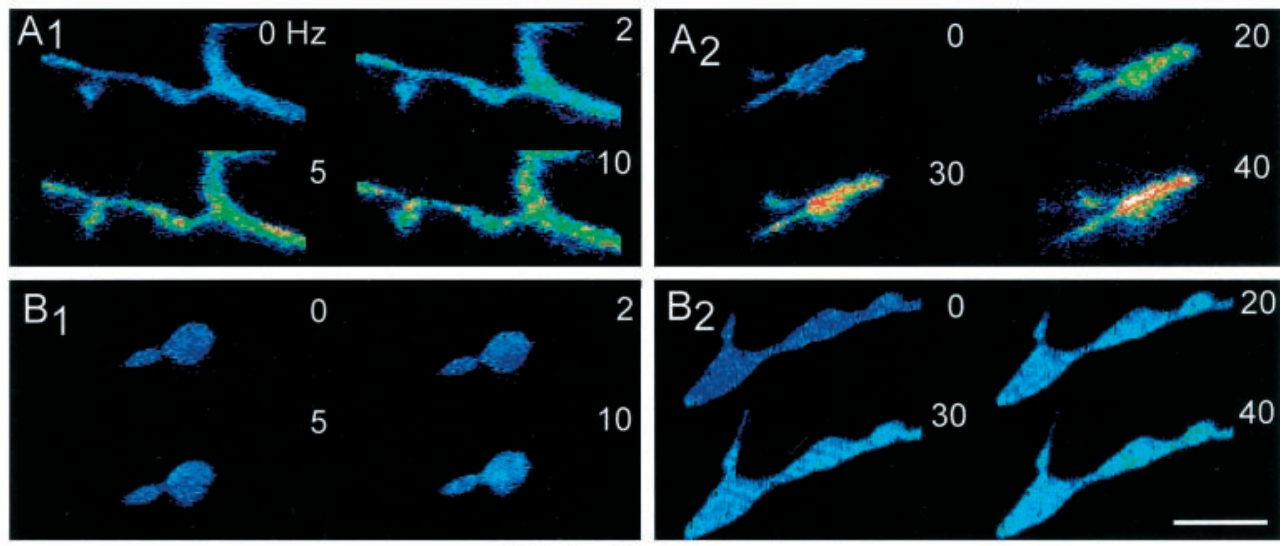

0 $1500 \mathrm{nM}$ raised, the signal continued to increase up to $50 \mathrm{~Hz}$ (Figs. 4, 5). Phasic terminals showed an easily detectable signal at $1 \mathrm{~Hz}$ and at all frequencies tested had a larger calcium response than tonic terminals (Figs. 4, 5). At the higher frequencies, some of the records showed irregularities possibly caused by movement during the imaging (Fig. 5B); therefore, in these measurements comparisons between phasic and tonic terminals were limited to the lower frequencies $(1-10 \mathrm{~Hz})$.

Measurements with fura-2 showed a clear difference in $\left[\mathrm{Ca}^{2+}\right]_{\mathrm{i}}$ between phasic and tonic terminals at any given frequency (Figs. $4,6)$. In general, calcium signals at low frequencies were harder to detect with fura-2 than with Calcium Green-1, but measurements at the higher frequencies were more accurate because of the higher $K_{\mathrm{d}}$ of fura-2.

As indicated in Figures 4-6, the calcium signal was larger in phasic terminals at all frequencies for both indicators. When the change in calcium signal is plotted against facilitation of transmitter release, a large difference between the two axons is apparent (Fig. $5 F$ ). Despite increasing calcium accumulation at higher frequencies, transmitter release remains close to its $1 \mathrm{~Hz}$ value in phasic axons, implying that the synapses are operating close to their maximum capacity at $1 \mathrm{~Hz}$. Therefore, factors other than calcium entry limit transmitter output at phasic terminals. In contrast, tonic terminals increase their transmitter release with frequency in parallel with increased total calcium entry and accumulation, but even at $20 \mathrm{~Hz}$ or more they do not approach the quantal release values seen at phasic terminals. The relative calcium signal is considerably larger in tonic terminals at 10 and $20 \mathrm{~Hz}$ than in phasic terminals at $1 \mathrm{~Hz}$, indicating that tonic terminals release less transmitter for a given change in $\left[\mathrm{Ca}^{2+}\right]_{\mathrm{i}}$ (Fig. 5E).

For the Calcium Green-1 data, estimates of the change in calcium with stimulation $\left(\Delta \mathrm{Ca}^{2+}\right)$ were obtained by using the resting $\left[\mathrm{Ca}^{2+}\right]_{\mathrm{i}}$ values from the fura-2 measurements and applying the semilogarithmic relationship between $\Delta F / F$ and $\left[\mathrm{Ca}^{2+}\right]_{i}$ (Fig. 1). For both terminals, a nearly linear relationship between $\Delta \mathrm{Ca}^{2+}$ and frequency resulted (Fig. $5 E$ ). This is in accord with the linear relationship between $\Delta \mathrm{Ca}^{2+}$ and frequency reported by 

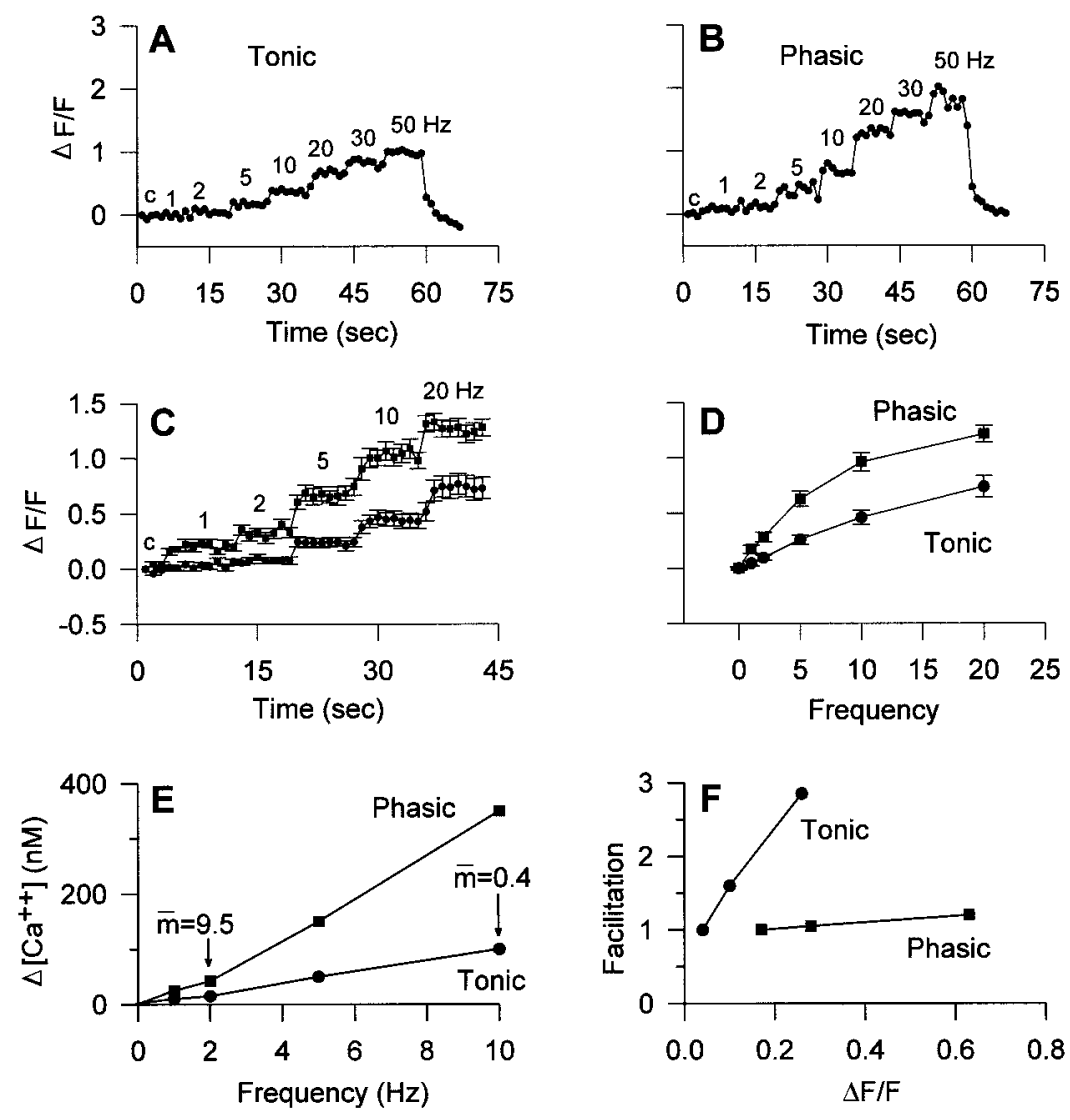

Figure 5. Frequency dependence of the relative calcium signals $(\Delta F / F)$ from phasic and tonic terminals injected with Calcium Green-1 and estimated changes in intraterminal $\left[\mathrm{Ca}^{2+}\right]$ with frequency. Individual tonic $(A)$ and phasic $(B)$ terminals were followed in an experiment in which the axons were stimulated sequentially for $8 \mathrm{sec}$ periods at frequencies ranging from 1 to $50 \mathrm{~Hz}$, as indicated. The fluorescence values were normalized to the unstimulated (control) response $(c)$ for each set after subtracting the background fluorescence from both resting and stimulated fluorescence values. $C$, Summary of data from 17 tonic and 23 phasic terminals measured as shown in $A$ and $B$; data obtained at $1-20 \mathrm{~Hz}$ are shown. $D$, Frequency dependence of the calcium signals, shown by averaging the normalized fluorescence measurements of the eight frames obtained at each frequency in $C$. Note that the relationship is curvilinear. $E$, Estimated changes in calcium $\left(\Delta\left[\mathrm{Ca}^{2+}\right]\right)$ at frequencies of $1-10 \mathrm{~Hz}$, obtained from $D$ by applying calibration of Calcium Green-1 fluorescence (Fig. 1). The increase in $\left[\mathrm{Ca}^{2+}\right]$ is approximately linear with frequency. Average values for quantal content $(\overline{\mathrm{m}})$ from Table 1 are indicated for the tonic terminals at $10 \mathrm{~Hz}$ and for the phasic terminals at $1 \mathrm{~Hz}$, illustrating that quantal output for tonic terminals is 24 times lower, although the estimated $\left[\Delta \mathrm{Ca}^{2+}\right]$ is four times higher. $F$, Relative facilitation values plotted against calcium signals $(\Delta F / F)$ in phasic and tonic terminals at 1,2 , and $5 \mathrm{~Hz}$. Values normalized to those at $1 \mathrm{~Hz}$. Increased calcium accumulation is accompanied by very little facilitation in phasic terminals, whereas tonic terminals show a large increase in facilitation as calcium signals increase with frequency of stimulation.
Tank et al. (1995) for the crayfish opener inhibitory axon's varicosities.

The fura-2 measurements also yielded a linear relationship between $\Delta \mathrm{Ca}^{2+}$ and frequency over a wider frequency range (Fig. 6). The values of $\Delta \mathrm{Ca}^{2+}$ were similar for the two sets of observations, but because these were obtained from different lots of crayfish, identical results would not be expected. Results for the phasic terminals agreed closely, whereas values for tonic terminals were higher in the Calcium Green-1 estimates. The calcium measurements represent an average intraterminal change after collapse of the transient calcium domains near the activated calcium channels, as discussed extensively by several authors (Delaney and Tank, 1994; Tank et al., 1995). In our records, a steady-state value of the calcium signal was reached rapidly (Figs. $5,6)$. The steady-state level is not sensitive to the concentration of calcium indicator in the terminal; it represents the outcome of a balance between influx and efflux (Tank et al., 1995). In crayfish opener muscle inhibitory axon terminals, the steady-state calcium change is linearly related to stimulation frequency (Tank et al., 1995). For the extensor muscle motor neurons, the relationship was also linear for both phasic and tonic terminals (Figs. 5, 6). Thus, the single-compartment model of Tank et al. (1995) is a good initial representation of calcium dynamics in the extensor motor terminals.

\section{Influence of varicosity size on $\mathrm{Ca}^{2+}$ signals}

We investigated the relationship between bouton size and $\Delta \mathrm{Ca}^{2+}$ for the two axons. When the calcium signal was measured in different-sized boutons of the same tonic terminals under the same conditions of stimulation, there was no discernable influence of bouton size (Fig. $7 A$ ). In addition, no size effect was found among varicosities of several different preparations when $\Delta F / F$ or
$\left[\mathrm{Ca}^{2+}\right]_{\mathrm{i}}$ was plotted against the estimated volume of the varicosity. This is best shown in a series of fura- 2 measurements (Fig. $7 B$ ). In comparing phasic and tonic terminals, it was clear that even when phasic and tonic varicosities of similar size were selected, the $\Delta \mathrm{Ca}^{2+}$ values were always larger for phasic varicosities at any given frequency (Fig. $7 B$ ). These observations indicate that within each type of bouton, calcium entry is scaled to the size of the varicosity. In varicosities, calcium entry occurs predominantly at synapses (Delaney et al., 1989). In previous work, it was found that within one type, larger varicosities have more synapses than smaller varicosities (Quigley et al., 1999); this could explain the lack of effect of varicosity size on $\Delta \mathrm{Ca}^{2+}$.

The scaling of calcium entry differs for phasic and tonic boutons, because even when boutons are of similar size, $\Delta \mathrm{Ca}^{2+}$ is always larger for phasic boutons at a given stimulation frequency. Neuron-specific scaling of synaptic spacing on boutons has been documented for Drosophila (Meinertzhagen et al., 1998) and apparently occurs also in crustacean phasic and tonic terminals, as indicated in Table 3.

\section{Time course of $\mathrm{Ca}^{2+}$ signals}

Different rates of $\mathrm{Ca}^{2+}$ accumulation could be caused by differences in $\mathrm{Ca}^{2+}$ extrusion (Tank et al., 1995). We therefore compared the rate of decline of $\Delta \mathrm{Ca}^{2+}$ in the two terminals when peak $\Delta \mathrm{Ca}^{2+}$ was the same in both. In addition, the initial rate of rise of $\Delta \mathrm{Ca}^{2+}$ was compared.

When the peak $\Delta \mathrm{Ca}^{2+}$ was the same for the two terminals, the rate of rise of the signal was almost identical (Fig. 8A,B). According to the single-compartment model (Tank et al., 1995), similarity in the initial rate of rise of the signal implies that the initial buffering of $\left[\mathrm{Ca}^{2+}\right]_{i}$ is similar for the two boutons. Thus, our present measurements do not indicate a difference in fast 
Figure 6. Averaged calcium signals from several fura-2injected phasic $(A)$ and tonic $(B)$ terminals during brief trains of stimulation at different frequencies. Stimulation frequency is shown over each trace; solid bar indicates the period of stimulation. The relationship between $\Delta \mathrm{Ca}^{2+}$ and frequency $(C)$ is linear for both types of bouton. Data points were averaged from 5-12 different boutons in three preparations and show mean \pm SEM. The slopes of the two lines differ approximately fivefold. Over the frequency range of $1-10 \mathrm{~Hz}$, the values estimated from fura- 2 agree well with those estimated from Calcium Green-1 (Fig. 5).

buffering, although total buffering capacity may be greater for the tonic axon, as shown by differential responses to calcium overload (Atwood and Lnenicka, 1992). The initial rate of rise of the signals varied with frequency, as expected, and was greater for the phasic axon at any given frequency, as would be the case for a larger impulse-linked calcium entry per volume of terminal (Fig. 8C).

In contrast, the rate of decline of $\left[\mathrm{Ca}^{2+}\right]_{\mathrm{i}}$ at the end of a train was invariably more rapid for the tonic varicosities for a given calcium load (Figs. 8, 9). The estimated time constant for the initial decay of $\left[\mathrm{Ca}^{2+}\right]_{\mathrm{i}}$ was approximately twice as large for the phasic axon (Table 2). This difference in initial rate of extrusion will influence the comparison of calcium entry for the two terminals, according to the one-compartment model of (Tank et al. 1995). The more efficient removal of $\left[\mathrm{Ca}^{2+}\right]_{i}$ in tonic axons accords with their normal pattern of maintained impulse production during locomotory activity, in contrast with phasic axons, which fire infrequently (Bradacs et al., 1997). A difference in $\mathrm{Ca}^{2+}$ extrusion has also been seen in phasic and tonic growth cones (Lnenicka et al., 1998).

There was evidence for two different processes in calcium removal (Fig. 9). At low frequencies, $\left[\mathrm{Ca}^{2+}\right]_{\mathrm{i}}$ decayed with a
A Phasic

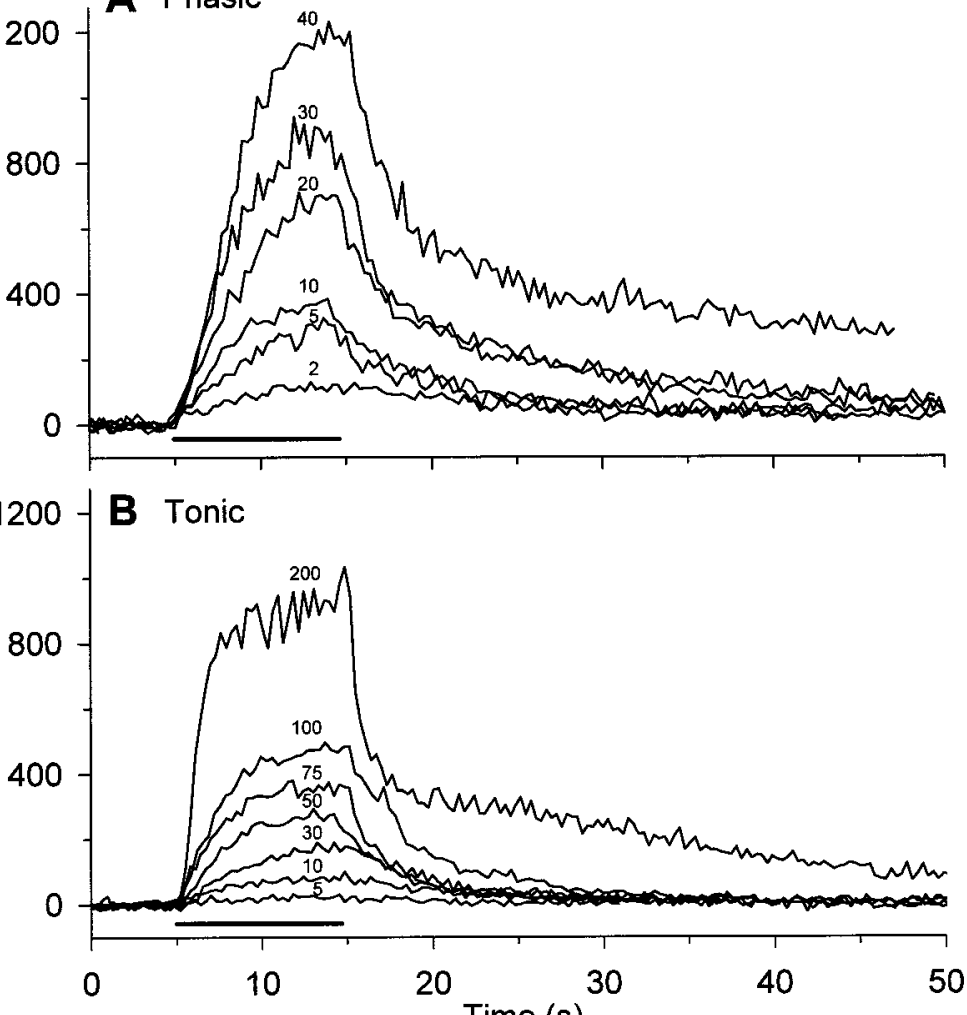

C

Time (s)

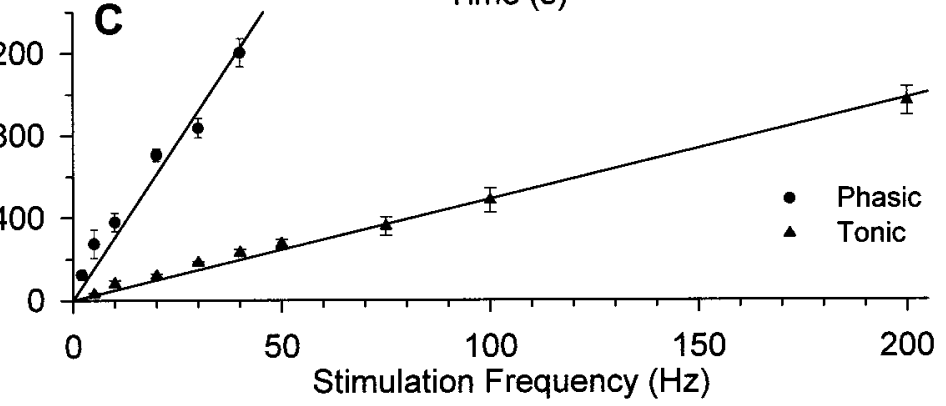

single exponential, but at higher frequencies two decay processes became evident. The slower phase of decay appeared at much lower frequencies for the phasic boutons. When the tonic axon was stimulated at a high frequency to induce a large calcium load, very similar decay kinetics, with two prominent phases, became apparent. The slow component may represent reaction of mitochondria (Tang and Zucker, 1997) or another unidentified process. It was not investigated further in the present study, and only the initial decay rate was taken into account in comparing bouton calcium entry at low frequencies.

It was of interest to know whether the amount of Calcium Green-1 or fura- 2 in the terminals influenced the $\mathrm{Ca}^{2+}$ removal rate, because the calcium indicator can affect the kinetics of extrusion (Tank et al., 1995). Among the varicosities in which the rate of extrusion had been estimated, several of similar size were found in which the resting fluorescence values differed. Plotting these values against the estimated extrusion rates showed no apparent relationship: varicosities with almost the same extrusion rates had different resting fluorescence values in several cases. Given that in many cases mean resting fluorescence values were not greatly different for phasic and tonic terminals, it is not likely that differences in concentration of the calcium indicators could 

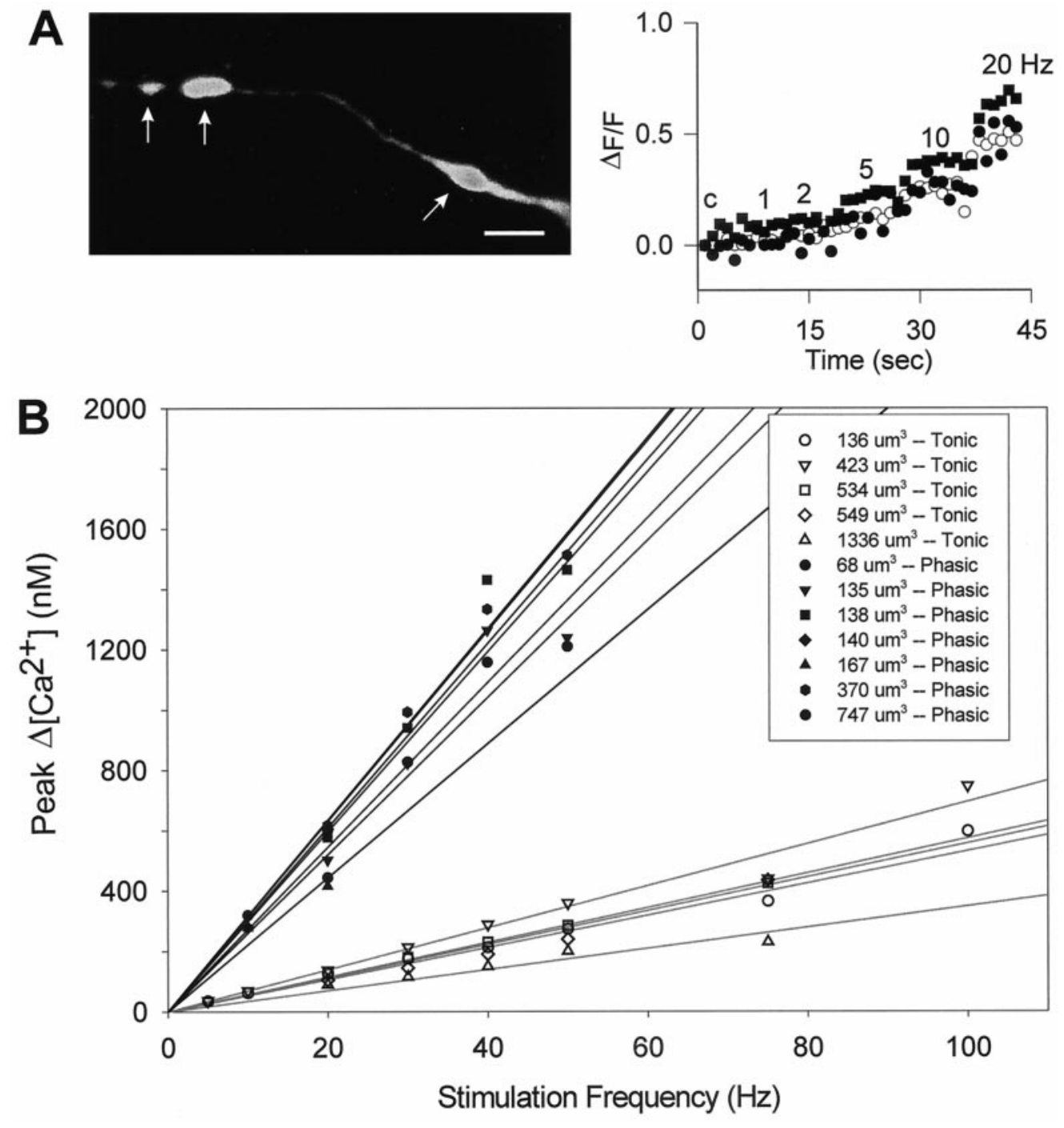

Figure 7. Analysis of the effect of bouton volume on calcium signal. $A$, Example from a Calcium Green-1injected tonic terminal in which calcium responses were measured in varicosities of different sizes (arrows). Scale bar, $12.5 \mu \mathrm{m}$. The graph shows development of calcium signals $(\Delta F / F)$ in the three different-sized tonic varicosities $(\bigcirc, \square, \bullet)$ over the frequency range of $1-20 \mathrm{~Hz}$, relative to the control (resting value, indicated by $c$ ). The varicosities ranged in size from 2 to 6 $\mu \mathrm{m}$ in diameter. There were no differences in relative calcium changes in boutons of different size along the same terminal over the frequency range of $1-20 \mathrm{~Hz}$. $B$, Calcium signals in tonic and phasic varicosities of different volumes from fura-2-injected axons. The tonic and phasic populations are clearly different, and the calcium signals do not depend on the size of the bouton within the tonic and phasic subclasses. Note that tonic and phasic boutons of similar size have markedly different calcium signals.

have produced the consistently observed difference in time constant for the decay of $\Delta \mathrm{Ca}^{2+}$ reported in Table 2. Additionally, fura-2 dye concentration was similar for both axons because fluorescence excited at $360 \mathrm{~nm}$ (which is insensitive to $\left[\mathrm{Ca}^{2+}\right]$ but sensitive to dye concentration) was comparable between them.

\section{Ultrastructure of synapses}

To determine the morphological counterparts for the physiological measurements (quantal content and calcium signals), we estimated the number of synapses and putative channel particles at synaptic active zones for the two terminals. In previous studies, we had tested the hypothesis that differences in the number of synapses or their size might be correlated with the higher quantal output of transmitter at the recording sites but found that these features could not account for transmission differences (King et al., 1996; Msghina et al., 1998). In fact, the number of synapses per varicosity or per unit length of terminal is larger for the tonic terminals, and mean synapse size is larger. Clearly, at $1 \mathrm{~Hz}$ the quantal output per synapse is much greater for phasic terminals. In the present study, we undertook additional freeze-fracture studies to determine whether it was likely that individual phasic synapses have more calcium channels in their active zones than tonic synapses. The occurrence of more calcium channels, if substantiated, could be one factor accounting for the difference in calcium signals, which might be linked in turn to the differences in transmitter release.

A major problem in examination of the freeze-fracture replicas was identification of phasic and tonic excitatory terminals and also inhibitory terminals that occur in limited regions of the specimens (Msghina and Atwood, 1997). Distinctions between excitatory and inhibitory terminals were made on the basis of previously elucidated differences in their postsynaptic receptor sites (Franzini-Armstrong, 1976; Pearce et al., 1986; Govind et al., 1995). Receptor site particles of excitatory axons, both phasic and tonic, characteristically appear on the muscle external (E)-face aligned in very regular rows, although occasionally the row-like arrangement is broken (Fig. 10A). Inhibitory receptor site particles, on the other hand, are more prominent on the muscle P-face where they are also regularly aligned, but in doublet rows (Fig. $10 B)$.

After this initial identification, fracture planes through the protoplasmic $(\mathrm{P})$-faces of the presynaptic terminals were particularly helpful in characterizing the synapses and active zones of the two excitatory axons. Identification of phasic and tonic nerve terminals in freeze-fracture replicas was based largely on size differences between them, especially when they occurred close to each other (Bradacs et al., 1997). As seen in Figure $2 A$, and in 

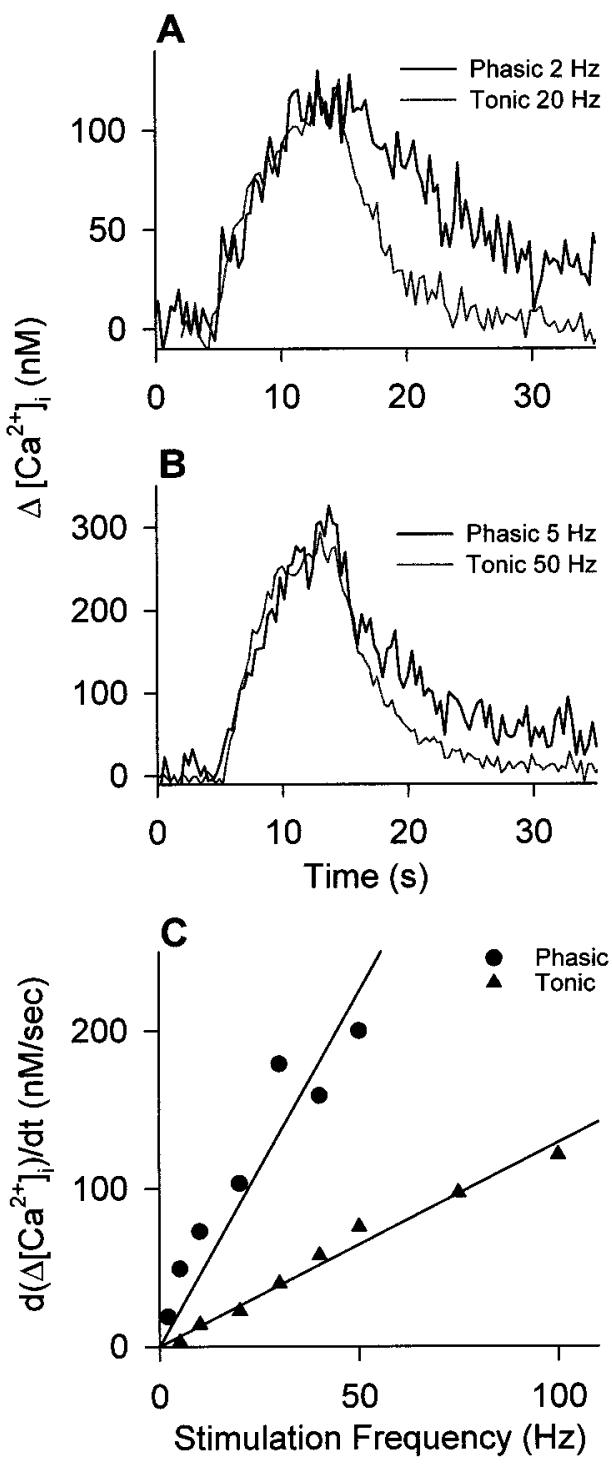

Figure 8. Comparison of the kinetics of calcium signals in phasic and tonic boutons of fura-2-injected axons. $A, B$, Two examples of representative records in which peak calcium was the same for the two boutons; signal rise times are almost identical, but the decay rate is slower for the phasic axon. $C$, Relationship between rate of rise of $\left[\mathrm{Ca}^{2+}\right]_{\mathrm{i}}$ and frequency for the two axons; the phasic axon shows a more rapid rate of rise at any given frequency.

accordance with previous studies, a consistent difference in overall morphology was apparent: phasic terminals are more slender and lack the prominent, relatively large varicosities of the tonic terminals (Atwood and Cooper, 1995; King et al., 1996; Bradacs et al., 1997). In transmission electron micrographs, synaptic contacts on both are qualitatively similar, as are active zones comprising presynaptic dense bars around which synaptic vesicles are docked (Fig. 10E). The putative calcium and calcium-activated potassium channels at these active zones become visible in the surface morphology of the synaptic membrane when it has been fractured along its lipid bilayer (Heuser and Reese, 1973; Heuser et al., 1974; Rheuben and Reese, 1978; Pearce et al., 1986; Walrond et al., 1993). However, to be certain of the identity of the terminals, we used only those that could be clearly identified as excitatory and for which the overall phasic-tonic differences in
Table 2. Comparison of the initial decay of $\left[\mathrm{Ca}^{2+}\right]_{\mathrm{i}}$ in phasic and tonic terminals matched for peak $\Delta\left[\mathrm{Ca}^{2+}\right]_{i}$

\begin{tabular}{lcllll} 
Phasic & & & Tonic & \\
\cline { 1 - 2 } $\begin{array}{lllll}\text { Peak } \\
\Delta\left[\mathrm{Ca}^{2+}\right]\end{array}$ & $\tau_{\text {initial }}(\mathrm{msec})$ & & $\begin{array}{l}\text { Peak } \\
\Delta\left[\mathrm{Ca}^{2+}\right]\end{array}$ & $\tau_{\text {initial }}(\mathrm{msec})$ & $\begin{array}{l}\text { Phasic/ } \\
\text { tonic ratio }\end{array}$ \\
\hline 124 & $11.39 \pm 4.3(6)$ & 120 & $4.11 \pm 0.6(9)$ & 2.77 \\
274 & $4.31 \pm 0.75(5)$ & 274 & $2.34 \pm 0.62(8)$ & 1.84 \\
379 & $4.26 \pm 0.62(12)$ & 358 & $2.30 \pm 0.18(4)$ & 1.85 \\
1200 & $2.08 \pm 0.28(7)$ & 963 & $0.80 \pm 0.07(3)$ & 2.60
\end{tabular}

Mean: 2.2

morphology were clearly apparent; these constraints severely limited the number of acceptable specimens.

The tonic terminals appeared as relatively large varicosities (diameter $2.20 \pm 0.97 \mu \mathrm{m}, n=8$, mean $\pm \mathrm{SD}$ in the present sample) with several synapses (Fig. 10C). Synapses were defined by roughly circular or oval elevations (plaques) that, except at the active zones, were relatively particle-sparse compared with the neighboring axolemma. Clusters of large particles indicating locations of ion channel structures (thought to be primarily calcium channels together with some calcium-activated potassium channels) denoted active zones, as in other well studied synapses (Pumplin et al., 1981; Roberts et al., 1990). Around the periphery of these active zones were occasional small circular depressions indicative of vesicle attachment or fusion sites (Fig. 10D). These images of fusion are induced and accumulated during chemical fixations and do not indicate the normal quantal release of the synapse but rather the preferred sites of vesicle fusion. The array of fusion images corresponds to the circle of docked vesicles around the presynaptic dense bar seen in thin sections (Fig. 10E). The same organization of the active zone was seen on the E-face of the fractured presynaptic membrane where vesicle attachment sites often appeared in a circle around a slight depression representing the active zone (Fig. $10 F$ ). These tonic active zones were circular in shape and contained on average of $\sim 15$ large membrane-associated particles (range $12-17 ; n=5$ ). In the tonic varicosity of Figure $10 C$, the larger synapses supported several active zones, whereas the smaller ones supported a single active zone. In synapses with multiple active zones, the center-to-center spacing between adjacent active zones was $217 \pm 25 \mathrm{~nm}(n=9$, mean $\pm \mathrm{SD})$.

The thin filiform terminals of the phasic axon (diameter $0.62 \pm$ $0.12 \mu \mathrm{m}, n=6$, mean $\pm \mathrm{SD}$ in this sample) showed a serial rather than grouped arrangement of the individual synaptic contacts (Fig. 11A). Otherwise they were qualitatively similar in appearance to the tonic synapses. Each phasic synapse possessed at least one active zone in which the large membrane-associated particles were clustered in a circular (Fig. $11 B, C$ ) or elongated (Fig. 11D) region. In one unusual example, four circular active zones occurred very close together, creating a long complex structure (Fig. $11 E)$. In the circular active zones, there were $\sim 15$ large particles $(n=3)$ but twice this number in a more distinctly elongated active zone. The center-to-center spacing between paired circular active zones of the same synapse was $88 \pm 46 \mathrm{~nm}(n=8$, mean \pm $\mathrm{SD}$ ), and this was significantly smaller (Student's $t$ test, $p<0.05$ ) than the spacing for the tonic synapses.

We were able to supplement these observations with additional images from the fast abdominal flexor muscles, in which tonic innervation does not occur (Kennedy and Takeda, 1965a,b), mak- 

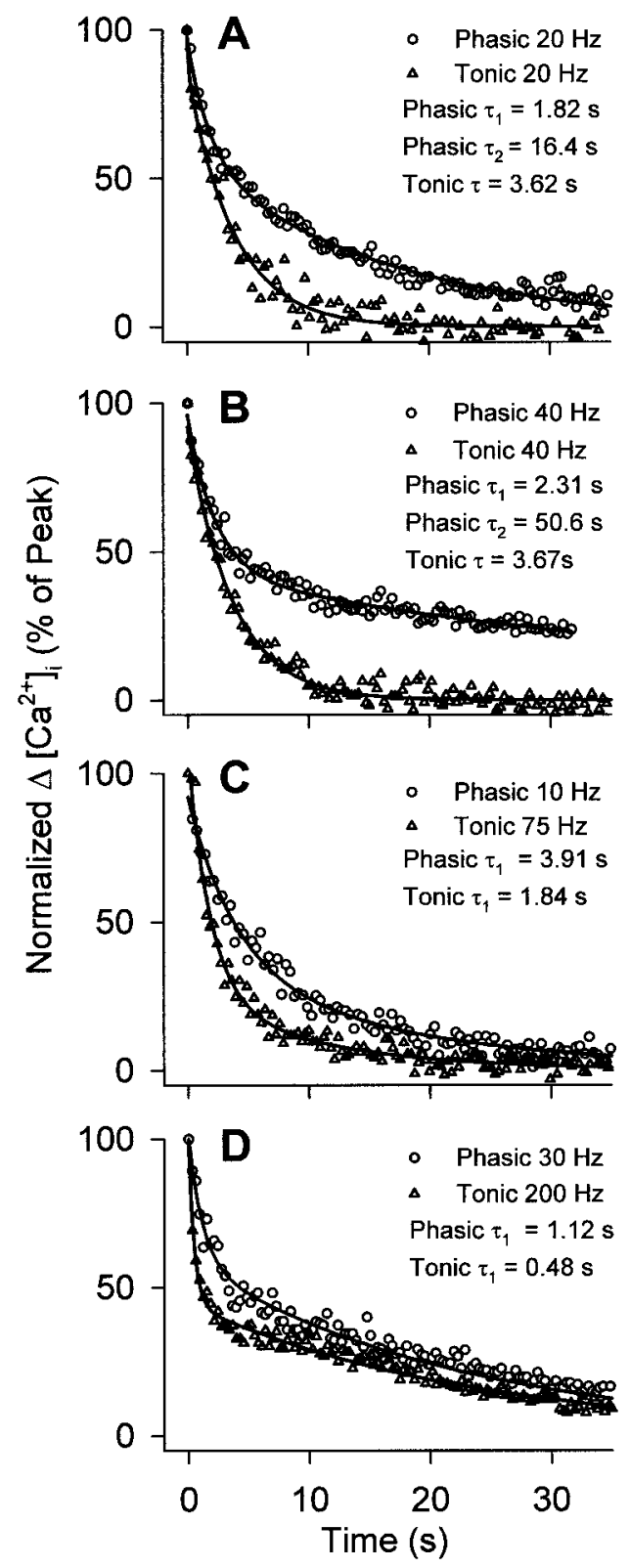

Figure 9. Comparison of the rates of decay of $\left[\mathrm{Ca}^{2+}\right]_{\mathrm{i}}$ in phasic and tonic boutons at the end of a stimulus train in fura-2-injected axons. $\left[\mathrm{Ca}^{2+}\right]_{\mathrm{i}}$ is normalized to a percentage of peak $\left[\mathrm{Ca}^{2+}\right]_{\mathrm{i}} . A, B$, Decay of $\left[\mathrm{Ca}^{2+}\right]$ in boutons receiving stimulus trains of equal frequency. At frequencies above $5 \mathrm{~Hz}$, decay of $\left[\mathrm{Ca}^{2+}\right]_{i}$ from phasic boutons is best described by a double-exponential model, made apparent by a pronounced slow phase. Conversely, tonic boutons exhibit decay of $\left[\mathrm{Ca}^{2+}\right]_{i}$, which is best described by a single exponential; however, tonic boutons did display a pronounced slow decay phase when subjected to a relatively high calcium load at frequencies above $50 \mathrm{~Hz}$. Representative traces averaged from several tonic and phasic boutons stimulated at 20 or $40 \mathrm{~Hz}$ are shown, with nonlinear regressions and decay time constants. Note the slow phase of decay exhibited by phasic terminals at these frequencies. $C, D$, Decay of $\left[\mathrm{Ca}^{2+}\right]_{\mathrm{i}}$ from tonic and phasic boutons subjected to similar peak calcium loads. Under similar peak calcium loads, tonic boutons display a more rapid initial decay of $\left[\mathrm{Ca}^{2+}\right]_{i}$. In the two representative cases, averaged from several boutons, initial decay was approximately twice as fast for tonic boutons. Data are given for two cases in which peak $\left[\mathrm{Ca}^{2+}\right]_{\mathrm{i}}$ was similar for both types of boutons. Table 2 shows this effect over a wider range of peak $\left[\mathrm{Ca}^{2+}\right]_{i}$. Nonlinear regressions are shown with initial decay time constants. ing the identification of phasic terminals much easier. In this material, circular active zones contained on average $13(n=10)$ particles and often occurred in closely associated pairs with a center-to-center spacing of $74 \mathrm{~nm}(n=12)$. These observations are in agreement with those for the phasic axon terminals of the leg extensor, which were more difficult to identify reliably.

Comparison of the collective results for phasic and tonic synapses indicates no major differences in active zone structure at this level of observation, apart from the occurrences of a few longer active zones in the phasic terminals. Also, as observed in transmission electron microscopy (King et al., 1996), active zones of phasic synapses were more likely to occur in closely spaced pairs, and in one case four closely spaced active zones were found. Generally, the results from the freeze-fracture replicas were in agreement with those from transmission electron microscopy (King et al., 1996).

We examined the relationship between the number of active zones and the size of the varicosity in a series of eight (tonic axon) varicosities reconstructed from serial electron micrographs in this study and previous ones (King et al., 1996; Msghina et al., 1998). We calculated the number of active zones per unit volume of varicosity. On average, there were $1.21 \pm 0.26$ (SE) active zones per cubic micrometer, and there was not a significant regression of these values on planar area or volume of the varicosity. From the data available in this sample, the ratio of active zones to volume of the varicosity did not change significantly with size of the varicosity. This accords with the data on $\Delta \mathrm{Ca}^{2+}$ and bouton size (Fig. 7).

The present study provides the first freeze-fracture views of parallel phasic and tonic crustacean synapses and an opportunity to compare upper limits of putative channel structures for the two terminals. Many of the structural features are very similar to those reported previously for insect synapses (Rheuben and Reese, 1978; Rheuben and Kammer, 1983; Rheuben, 1985). In both crustaceans and insects, limited numbers of active zone membrane particles occur in a cluster within the synaptic plaque, and release of vesicles occurs at edges of the cluster. In comparing fast (phasic) and slow (tonic) active zones in the moth Manduca, Rheuben (1985) found that there are more synapses (and active zones) in phasic junctions than in tonic and that the number of membrane particles per active zone is almost twice as great. Both features readily correlate with more vesicle release at phasic junctions. However, data on relative calcium entry and transmitter release per synapse are not available for these insect neuromuscular junctions, and in addition, some differences between them may relate to their occurrence on different target muscles and to differences in developmental stage. The differences reported for moth neuromuscular junctions do not hold for crustacean terminals if the comparison is made for equivalent lengths of terminal. Tonic terminals have more individual synapses and active zones per unit length (King et al., 1996) (Table 3), and although elongated or closely spaced active zones are more common in phasic terminals, an overall difference in the number of membrane particles per active zone was not demonstrated in the present study. The number and arrangement of prominent membrane-associated particles were approximately the same for similar-sized active zones of the two types of synapse. The prominent particles are thought to represent synaptic calcium channels and, in some cases, calcium-activated potassium channels (Pumplin et al., 1981; Roberts et al., 1990; Pawson et al., 1998).

In vertebrate (lizard) phasic and tonic motor nerve terminals, 

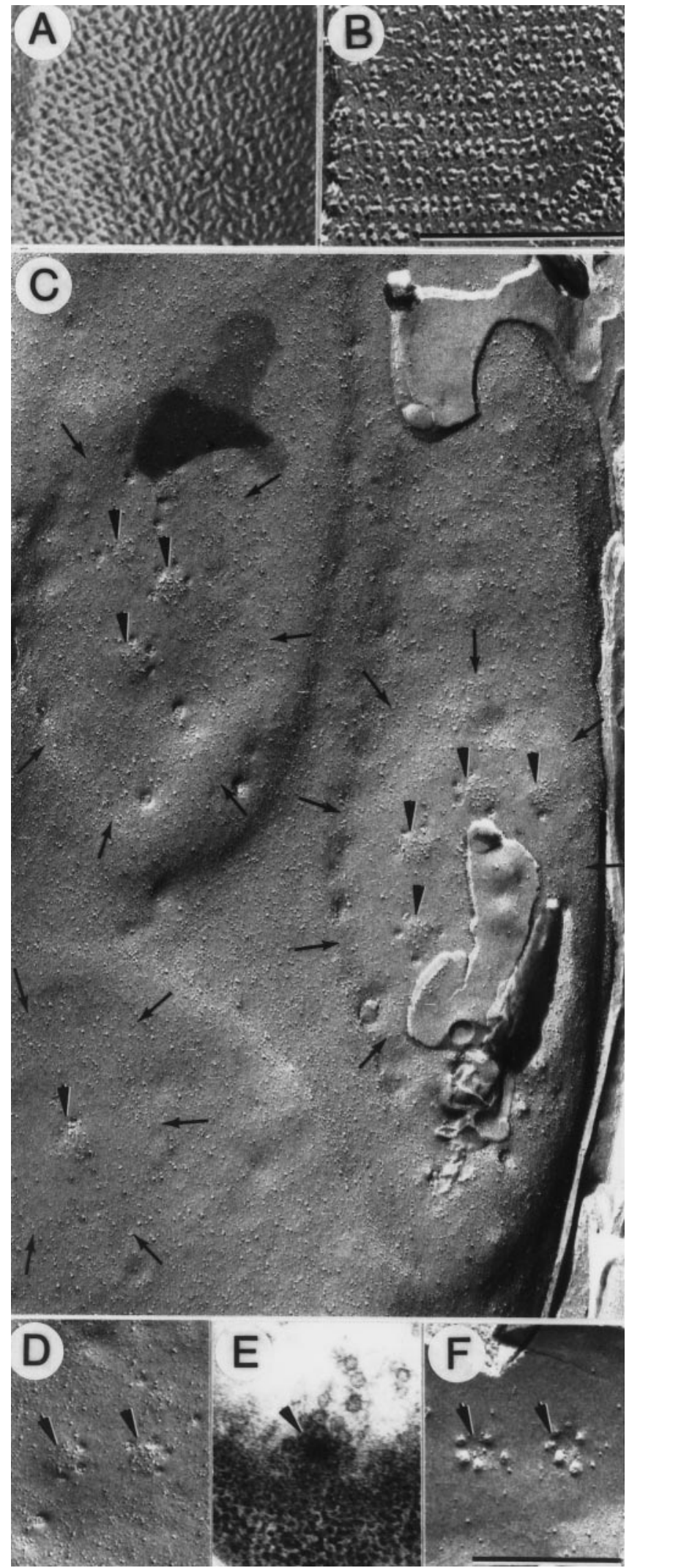

Figure 10. Intramembrane features of tonic synapses and active zones. $A, B$, Identification of excitatory and inhibitory synapses in freeze-fracture replicas. Receptor site particles occur in regular rows on the muscle E-face for the excitatory axon $(A)$ but as doublet rows on the muscle P-face for the inhibitory axon $(B)$. $C$, Part of a large varicosity of the tonic axon replicated on the axolemmal $\mathrm{P}$-face, which is rich in particles. This active zone numbers per terminal are similar, but the arrangement of active zone particles (putative calcium channels) differs greatly and could influence evoked release [Walrond and Reese (1985); for review, see Atwood and Lnenicka (1986)]. A comparable difference in active zone particle placement was not apparent in crayfish phasic and tonic terminals.

\section{Ultrastructural features and calcium entry}

An overall comparison of ultrastructural features and calcium entry for phasic and tonic boutons is presented in Table 3. The number of active zones per volume of bouton will influence $\Delta \mathrm{Ca}^{2+}$, assuming that the calcium channels per active zone are on average similar for the two types of bouton. From previous serial reconstructions of boutons (King et al., 1996), this value can be calculated. For $\Delta \mathrm{Ca}^{2+}$, the difference in peak values can be obtained from the linear relationships between peak $\Delta \mathrm{Ca}^{2+}$ and frequency (Figs. 5E, 6C). The values for the fura-2 measurements are more reliable, because fewer assumptions are included in the estimate. Fluorescence values from fura- 2 experiments show a fivefold difference in accumulation of $\left[\mathrm{Ca}^{2+}\right]_{\mathrm{i}}$ during stimulation. The observed values must be normalized for extrusion rate. We did this by multiplying those observed for the tonic axon by a factor of 2.2 to correct for the more rapid extrusion rate, as estimated from the initial time constant of decay (Table 2). As shown in Table 3, the morphological features indicate a 2.5- to 3.5 -fold difference in active zone number, or total active zone length, per terminal volume. For $\Delta \mathrm{Ca}^{2+}$, used as an estimate of $\left[\mathrm{Ca}^{2+}\right]_{\mathrm{i}}$ accumulation during a train of stimuli, the values corrected for extrusion rate yield an estimated $\mathrm{Ca}^{2+}$ entry that is 2.3 times greater for phasic boutons at low frequencies of stimulation. This ratio is comparable to those for the morphological features. Thus, the difference in estimated $\mathrm{Ca}^{2+}$ entry per bouton can be explained by the difference in active zones per volume of bouton, on the assumption that individual active zones admit, on average, similar amounts of $\mathrm{Ca}^{2+}$ per impulse for the phasic and tonic boutons. This implies that $\mathrm{Ca}^{2+}$ channels at active zones behave similarly in both terminals.

\section{DISCUSSION}

In the present study, the large difference in quantal release effectiveness of phasic and tonic synapses was correlated with calcium signals in the terminals during stimulation, and with active zone ultrastructure, to determine the role of calcium entry at active zones in generating differences in transmitter release.

Synaptic differentiation of phasic and tonic synapses involves a large difference in the probability of quantal release per synapse. Our previous observations on three-dimensional reconstructions of recording sites have shown that if the quantal content at a recording site is divided by the number of synapses at that site, the quantal release per synapse is 100-1000 times greater for the phasic terminal for a single nerve action potential (Msghina et al.,

\section{$\leftarrow$}

region shows three synapses (delineated by small arrows), each slightly elevated and containing relatively few particles except for collections of large particles at putative active zones (arrowheads). D, P-face view of two putative active zones (arrowheads) with a circular cluster of large active zone particles and several small circular depressions along the periphery representing attachment sites of synaptic vesicles. $E$, Thin section of a grazing view of a presynaptic dense bar (arrowhead) with synaptic vesicles docked around its periphery. $F$, E-face of active zone (arrowheads) with a circle of small dome-shaped protrusions representing attachment sites of synaptic vesicles surrounding a particle-free clear area. Scale bars: $A, B$, $0.2 \mu \mathrm{m} ; C-F, 0.4 \mu \mathrm{m}$. Magnification: $A, B, 141,000 \times$; C-F, 49,000×. 


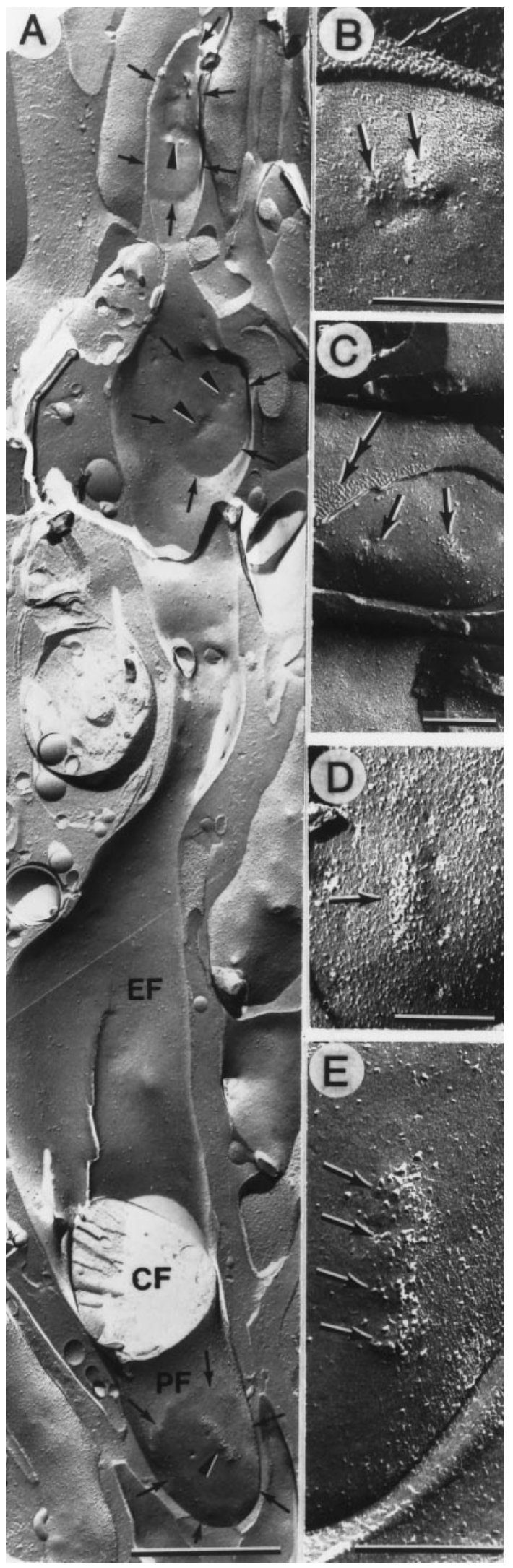

Figure 11. Intramembrane features of phasic synapses and active zones. $A$, Fracture through a thin filiform nerve terminal characteristic of the phasic axon. For most of its $8 \mu \mathrm{m}$ length the fracture plane is through the axolemmal E-face $(E F)$ but then passes through a cross-fracture $(C F)$ before exposing the axolemmal P-face $(P F)$. Three synaptic contacts
Table 3. Comparison of terminal structural parameters and calcium signals

\begin{tabular}{llll} 
& Phasic & Tonic & $\begin{array}{l}\text { Phasic/ } \\
\text { tonic ratio }\end{array}$ \\
\hline $\begin{array}{l}\text { Terminal volume } \\
\quad 1 \mu \mathrm{m} \text { terminal length })\end{array}$ & $1.20 \mu \mathrm{m}^{3}$ & $4.8 \mu \mathrm{m}^{3}$ & \\
$\begin{array}{l}\text { Active zones } \\
\quad(1 \mu \mathrm{m} \text { terminal length })\end{array}$ & 2.55 & 3.63 & \\
$\begin{array}{l}\text { Active zones per volume } \\
\quad\left(1 \mu \mathrm{m}^{3} \text { of terminal }\right)\end{array}$ & 2.13 & 0.76 & 2.8 \\
$\begin{array}{l}\text { Active zone total length } \\
\quad(1 \mu \mathrm{m} \text { terminal length })\end{array}$ & $0.32 \mu \mathrm{m}$ & $0.37 \mu \mathrm{m}$ & \\
$\begin{array}{l}\text { Active zone total length } \\
\text { per volume }\end{array}$ & $0.26 \mu \mathrm{m}$ & $0.08 \mu \mathrm{m}$ & 3.3 \\
$\quad\left(1 \mu \mathrm{m}^{3}\right.$ of terminal $)$ & & & \\
$\begin{array}{l}\left.\text { Peak Ca }{ }^{2+} \text { values (fura- }\right) \\
\text { Correction for extrusion rate }\end{array}$ & & & 5.0 \\
\hline
\end{tabular}

Structural features are from King et al. (1996). Regression lines of Figure 6 were used to compare peak $\mathrm{Ca}^{2+}$.

1998). Even allowing for the possibility that not all synapses are equally likely to transmit (Jahromi and Atwood, 1974; Wojtowicz et al., 1994), there is a substantial difference (two to three orders of magnitude) in release efficacy per synapse.

How does such a large difference arise? Several hypotheses can be raised for examination. (1) More calcium entry per impulse occurs at phasic active zones, because of the occurrence of more calcium channels, a higher probability of channel opening, or a larger channel conductance; (2) the arrangement of calcium channels relative to releasable synaptic vesicles is more conducive to release when a channel is opened by an action potential at a phasic synapse (Walrond and Reese, 1985); (3) the number of docked vesicles at the active zones, thought to be a determinant of release probability at mammalian synapses (Harris and Sultan, 1995; Schikorski and Stevens, 1997), is greater for phasic synapses; (4) the availability, proportions, or specific properties of proteins involved in vesicle docking, priming, and fusion (Südhof, 1995), or in regulation of calcium-dependent release (Parnas et al., 1991; Linial et al., 1997), generate overall greater calcium sensitivity of the release mechanism at the phasic synapse.

\section{Active zone structure}

The hypothesis that individual phasic active zones possess more calcium channels than their tonic counterparts was not sustained by the present observations, because active zone particle counts were similar for individual active zones of the two types of varicosity. Longer active zones, seen at some phasic synapses,

(delineated by small arrows) are seen in register along the terminal; two are in the E-face and one is in the P-face. Active zones (arrowheads) occur within each synapse. $B$, Synaptic contact with two clusters of large particles at two closely adjacent active zones (arrows). From the P-face, the fracture plane jumps to the muscle E-face and shows the characteristic arrangement of excitatory synaptic receptor particles (double arrow). $C$, Synapse with two active zones (arrows) on a synapse adjacent to which characteristic receptor zone particles (double arrow) are seen on the muscle E-face. $D$, An elongated active zone (arrow) with a clustering of large particles and a vesicle fusion image at its edge. $E$, Enlarged view of a phasic synapse showing a synaptic contact with a collection of large particles in a complex structure consisting of four adjacent circular active zones (arrows). Scale bars: $A, 1 \mu \mathrm{m} ; B-E, 0.2 \mu \mathrm{m}$. Magnification: $A$, $25,600 \times ; B, 93,000 \times C, 50,400 \times D, 69,750 \times ; E, 105.000 \times$. 
have proportionately more membrane particles (Walrond et al., 1993), which could in principle lead to more transmitter release per impulse, but only to the limit of the number of docked and primed vesicles available. There is not a sufficient size difference in phasic and tonic active zones to yield a 100- to 1000-fold difference in release per synapse (King et al., 1996) (Table 3). Hypothesis (2) relating the differences in synaptic performance to docked vesicles is inadequate to explain the large physiological differences of crustacean synapses. Also, the distribution of particles within the active zones was not markedly different; in both types of synapse, they occur over the whole active zone region, some close to the periphery (near vesicle docking sites) and some in the center of the active zone. Thus, neither the total number of active zone particles nor their distribution provides support for a numerical or positional superiority that can account for a large difference in probability of transmitter release per synapse.

One assumption that is inherent in the comparison of the synaptic particles of phasic and tonic synapses is that most of them represent calcium channels in each case. Strong arguments for this have been advanced in studies of other synapses (Pumplin et al., 1981; Roberts et al., 1990). There are also grounds for this assumption in the crayfish from previous calculations of Tank et al. (1995), who estimated that there would have to be $\sim 50$ channels (with unitary conductance of $0.5 \mathrm{pS}$ ) opened per release site at synapses of crayfish inhibitory terminals to account for the observed calcium entry per impulse. This is more than the number of particles per active zone observed on average in freezefracture material (Govind et al., 1995). However, if the channel conductance were larger than the assumed value of $0.5 \mathrm{pS}$, the number of channels required would be smaller, and closer to the number of active zone particles observed in crayfish terminals. These calculations also indicate that the probability of channel opening for both phasic and tonic terminals must be quite high to account for the observed calcium entry, if the observed synaptic active zone particles are calcium channels of $0.5-1 \mathrm{pS}$ conductance. This is a different situation than that envisioned by Pumplin et al. (1981) for the squid giant synapse: only $10 \%$ of the available calcium channels were estimated to be opened by one impulse. In recent studies of mammalian central synapses, the available evidence also suggests a relatively high probability of calcium channel opening (Sabatini and Regehr, 1997). Thus, the balance of available evidence from crayfish and mammalian synapses supports the view that channel opening probability is relatively high. If this is the case, calcium channels may behave similarly in crayfish phasic and tonic synapses and are not likely to be the major factor responsible for the phasic-tonic difference in transmitter release.

\section{Calcium signals}

Because phasic terminals are generally smaller than tonic terminals, the difference in relative calcium build-up (Table 3) could arise from a similar amount of calcium entering a smaller volume of terminal axoplasm. To estimate the relative $\mathrm{Ca}^{2+}$ entry per active zone, we calculated and compared the number of active zones per volume of terminal, and the total length of the active zone structures per volume of terminal (which takes into account the longer phasic active zones), using data from serial electron microscopy (King et al., 1996). As shown in Table 3, the phasic/ tonic structural ratios are very close to the ratios for the estimated calcium entry, when differences in extrusion rate are taken into account. The build-up of calcium in tonic varicosities is counteracted by more rapid calcium extrusion (Figs. 8, 9; Table 2). At present, the most economical hypothesis is that the calcium channels of the two terminals do not differ greatly in their ability to admit $\mathrm{Ca}^{2+}$ during a nerve impulse. In accordance with the principle of Occam's razor, it is not necessary to postulate significant differences in the calcium channels themselves (opening probabilities, open times, or channel conductances). It must be remembered that the $\mathrm{Ca}^{2+}$ signals reported here represent the accumulation of $\mathrm{Ca}^{2+}$ during repetitive stimulation. The $\mathrm{Ca}^{2+}$ signal in the microdomains responsible for transmitter release to a single action potential (Augustine et al., 1991; Llinas et al., 1992) could not be observed with the methods used in this study and may or may not differ, depending on various factors such as intracellular $\mathrm{Ca}^{2+}$ buffers near the channels (Stern, 1992). If the microdomains are more restricted by local buffers with fast binding kinetics in tonic terminals, the probability of release per channel and per active zone could be reduced. This possibility would have to be assessed by further experiments.

\section{Difference in calcium sensitivity of release}

The large difference in the initial transmitter release at low frequency $(1 \mathrm{~Hz})$ cannot be readily explained by differences in the number or size of synapses, differences in putative channel particles in the active zone, or a difference in calcium entry at the active zone. The hypothesis that best accounts for our observations is a difference in calcium sensitivity of release. This could account for the lower release associated with larger total calcium entry in tonic terminals at 10 and $20 \mathrm{~Hz}$, compared with higher release and smaller total calcium entry in phasic terminals at $1 \mathrm{~Hz}$ (Fig. $5 E$ ), and also for the near-maximal release at $1 \mathrm{~Hz}$ in phasic synapses (Figs. 3, 4). Simply stated, more release occurs with less $\mathrm{Ca}^{2+}$ entry for phasic terminals at $1 \mathrm{~Hz}$ than for tonic terminals at 10 and $20 \mathrm{~Hz}$. This supports a difference in calcium sensitivity of the release mechanism in the two neurons.

There are numerous precedents for changes in calcium sensitivity at synapses. For example, a change in calcium sensitivity of release, rather than calcium entry, appears to enhance release at the frog neuromuscular junction when second-messenger systems are altered (Redman et al., 1997). Similarly, transmitter release is greatly enhanced by serotonin at the crustacean neuromuscular junction and involves activation of second-messenger systems (Dixon and Atwood, 1989a,b), but the enhanced release occurs without any change in calcium entry in the terminal varicosities (Delaney et al., 1991). In bovine adrenal chromaffin cells, $\mathrm{Ca}^{2+}$ sensitivity of exocytosis is modulated by the Rab3A protein (Johannes et al., 1998). Yet another example is reported in work on the squid giant synapse, in which calcium-dependent changes in calcium sensitivity of release have been reported (Hsu et al., 1996).

Regulatory proteins may be differentially expressed in motor neurons and could modulate transmitter release. The calciumbinding protein frequenin, initially discovered in Drosophila (Pongs et al., 1993), is known to enhance transmission both in Drosophila (Pongs et al., 1993; Rivosecchi et al., 1994) and in Xenopus (Olafsson et al., 1995) neuromuscular junctions. We have found that the crustacean version of this protein is selectively expressed in phasic rather than tonic terminals (Atwood et al., 1995) and is therefore a logical choice for investigation as a modulator of synaptic functional differentiation, perhaps through an influence on calcium sensitivity.

\section{REFERENCES}

Atwood HL (1967) Variation in physiological properties of crustacean motor synapses. Nature 215:57-58. 
Atwood HL (1976) Organization and synaptic physiology of crustacean neuromuscular systems. Prog Neurobiol 7:291-391.

Atwood HL, Bittner GD (1971) Matching of excitatory and inhibitory inputs to crustacean muscle fibers. J Neurophysiol 34:157-170.

Atwood HL, Cooper RL (1995) Functional and structural parallels in crustacean and Drosophila neuromuscular systems. Am Zool 35:556-565.

Atwood HL, Lnenicka GA (1986) Structure and function in synapses: emerging correlations. Trends Neurosci 9:248-250.

Atwood HL, Lnenicka GA (1992) Differential effects of calcium entry on phasic and tonic motor axons of crayfish. Soc Neurosci Abstr 18:246.

Atwood HL, Wojtowicz JM (1986) Short-term and long-term plasticity and physiological differentiation of crustacean motor synapses. Int Rev Neurobiol 28:275-362.

Atwood HL, Msghina M, Lindemeier H, Pongs O (1995) Homologue of Drosophila neural protein frequenin selectively expressed in crustacean phasic motor terminals. Soc Neurosci Abstr 21:709.6.

Augustine GJ, Charlton MP (1986) Calcium dependence of presynaptic calcium current and post-synaptic response at the squid giant synapse. J Physiol (Lond) 381:619-640.

Augustine GJ, Adler EM, Charlton MP (1991) The calcium signal for transmitter secretion from presynaptic nerve terminals. Ann NY Acad Sci 635:365-381.

Bittner GD (1968) Differentiation of nerve terminals in the crayfish opener muscle and its functional significance. J Gen Physiol 5:731-758.

Bradacs H, Cooper, RL, Msghina M, Atwood HL (1997) Differential physiology and morphology of phasic and tonic motor axons in a crayfish limb extensor muscle. J Exp Biol 200:677-691.

Cooper RL, Marin L, Atwood HL (1995a) Synaptic differentiation of a single motor neuron: conjoint definition of transmitter release, presynaptic calcium signals, and ultrastructure. J Neurosci 15:4209-4222.

Cooper RL, Stewart BA, Wojtowicz JM, Wang S, Atwood HL (1995b) Quantal measurement and analysis methods compared for crayfish and Drosophila neuromuscular junctions, and rat hippocampus. J Neurosci Methods 61:67-78.

Davis GW, Murphey RK (1994) Retrograde signaling and the development of transmitter release properties in the invertebrate nervous system. J Neurobiol 25:740-756.

Delaney KR, Tank DW (1994) A quantitative measurement of the dependence of short-term synaptic enhancement on presynaptic residual calcium. J Neurosci 14:5885-5902.

Delaney KR, Zucker RS, Tank DW (1989) Calcium in motor nerve terminals associated with posttetanic potentiation. J Neurosci 9:3558-3567.

Delaney KR, Tank DW, Zucker RS (1991) Presynaptic calcium and serotonin-mediated enhancement of transmitter release at crayfish neuromuscular junction. J Neurosci 11:2631-2643.

Dixon D, Atwood HL (1989a) Phosphatidylinositol system's role in serotonin facilitation at the crayfish neuromuscular junction. J Neurophysiol 62:239-246.

Dixon D, Atwood HL (1989b) Adenylate cyclase system is essential for long-term facilitation at the crayfish neuromuscular junction. J Neurosci 9:4246-4252.

Dobrunz LE, Stevens CF (1997) Heterogeneity of release probability, facilitation, and depletion at central synapses. Neuron 18:995-1008.

Dudel J (1965) Potential changes in the crayfish motor nerve terminal during repetitive stimulation. Pflügers Arch 282:323-337.

Dudel J (1981) The effect of reduced calcium on quantal unit current and release at the crayfish neuromuscular junction. Pflügers Arch 391:35-40.

Franzini-Armstrong C (1976) Freeze-fracture of excitatory and inhibitory synapses in crayfish neuromuscular junctions. J Microsc Biol Cell 25:217-222.

Govind CK, Pearce J, Wojtowicz JM, Atwood HL (1994) “Strong” and "weak" synaptic differentiation in the crayfish opener muscle: structural correlates. Synapse 16:45-58.

Govind CK, Atwood HL, Pearce J (1995) Inhibitory axoaxonal and neuromuscular synapses in the crayfish opener muscle: membrane definition and ultrastructure. J Comp Neurol 351:476-488.

Grynkiewicz GM, Poenie M, Tsien RY (1985) A new generation of $\mathrm{Ca}^{2+}$ indicators with greatly improved fluorescence properties. J Biol Chem 260:3440-3450.

Harris KM, Sultan P (1995) Variation in the number, location and size of synaptic vesicles provides an anatomical basis for the nonuniform probability of release at hippocampal CA1 synapses. Neuropharmacology 34:1387-1395.

Haydon PG, Henderson E, Stanley EF (1994) Localization of individual calcium channels at the release face of a presynaptic nerve terminal. Neuron 13:1275-1280.

Herrera AA, Grinnell AD, Wolowske B (1985) Ultrastructural correlates of naturally occurring differences in transmitter release efficacy in frog motor nerve terminals. J Neurocytol 14:193-202.

Heuser JE, Reese TS (1973) Evidence for recycling of synaptic vesicle membrane during transmitter release at the frog neuromuscular junction. J Cell Biol 57:315-344.

Heuser JE, Reese TS, Landis DMD (1974) Functional changes in frog neuromuscular junctions studied with freeze-fracture. J Neurocytol 3:109-131.

Hsu SF, Augustine GJ, Jackson MB (1996) Adaptation of $\mathrm{Ca}^{2+}$ triggered exocytosis in presynaptic terminals. Neuron 17:501-512.

Jahromi SS, Atwood HL (1974) Three-dimensional ultrastructure of the crayfish neuromuscular apparatus. J Cell Biol 63:599-613.

Johannes L, Lledo PM, Chameau P, Vincent JD, Henry JP, Darchen F (1998) Regulation of the $\mathrm{Ca}^{2+}$ sensitivity of exocytosis by Rab3a. J Neurochem 71:1127-1133.

Kennedy D, Takeda K (1965a) Reflex control of abdominal flexor muscles in the crayfish. I. The twitch system. J Exp Biol 43:211-227.

Kennedy D, Takeda K (1965b) Reflex control of abdominal flexor muscles in crayfish. II. The tonic system. J Exp Biol 43:229-246.

King MJR, Atwood HL, Govind CK (1996) Structural features of crayfish phasic and tonic neuromuscular junctions. J Comp Neurol 372:618-626.

Linial M, Ilouz N, Parnas H (1997) Voltage-dependent interaction between the muscarinic Ach receptor and proteins of the exocytic machinery. J Physiol (Lond) 504.2:251-258.

Llinas R, Sugimori M, Silver RB (1992) Microdomains of high calcium concentration in a presynaptic terminal. Science 256:677-679.

Lnenicka GA (1991) The role of activity in the development of phasic and tonic synaptic terminals. Ann NY Acad Sci 627:197-211.

Lnenicka GA, Arcaro KF, Calabro JM (1998) Activity-dependent development of calcium regulation in growing motor axons. J Neurosci 18:4966-4972.

Meinertzhagen IS, Govind CK, Stewart BA, Carter JM, Atwood HL (1998) Regulated spacing of synapses and presynaptic active zones at larval neuromuscular junctions in different genotypes of the flies Drosophila and Sarcofaga. J Comp Neurol 393:482-492.

Msghina M, Atwood HL (1997) Distribution and morphology of inhibitory innervation in crayfish (Procambarus clarkii) limb and abdominal muscles. Cell Tissue Res 290:111-118.

Msghina M, Charlton MP, Atwood HL (1995) Differentiation of transmitter release properties and calcium transients in phasic and tonic motor nerve endings of crustacea. Soc Neurosci Abstr 21:138.15.

Msghina M, Govind CK, Atwood HL (1998) Synaptic structure and transmitter release in crustacean phasic and tonic motor neurons. J Neurosci 18:1374-1382.

Murthy VN, Sejnowski TJ, Stevens CF (1997) Heterogeneous release properties of visualized individual hippocampal synapses. Neuron 18:599-612.

Olafsson P, Wang T, Lu B (1995) Molecular cloning and functional characterization of the Xenopus $\mathrm{Ca}^{2+}$-binding protein frequenin. Proc Natl Acad Sci USA 92:8001-8005.

Ortiz CL (1972) Crayfish neuromuscular junction: facilitation with constant nerve terminal potential. Experientia 28:1035-1036.

Parnas I, Parnas H, Dudel J (1982) Neurotransmitter release and its facilitation in crayfish muscle. V. Basis for synapse differentiation of the fast and slow type in one axon. Pflügers Arch 395:261-270.

Parnas I, Parnas H, Hochner B (1991) Amount and time-course of release. The calcium hypothesis and the calcium-voltage hypothesis. Ann NY Acad Sci 635:177-190.

Pawson PA, Grinnell AD (1984) Posttetanic potentiation in strong and weak neuromuscular junctions: physiological differences caused by a differential $\mathrm{Ca}^{2+}$-influx. Brain Res 323:311-315.

Pawson PA, Grinnell AD, Wolowske B (1998) Quantitative freezefracture analysis of the frog neuromuscular junction synapse. I. Naturally occurring variability in active zone structure. J Neurocytol 27:361-377.

Pearce J, Govind C, Shivers RR (1986) Intramembranous organization of lobster excitatory neuromuscular synapses. J Neurocytol 15:241-252. 
Poenie M (1990) Alteration of intracellular fura-2 fluorescence by viscosity: a simple correction. Cell Calcium 11:85-91.

Pongs O, Lindemeier J, Zhu XR, Theil T, Engelcamp D, Krah-Jentgens I, Lambrecht H-G, Koch KW, Schwemer J, Rivosecchi R, Mallart A, Galceran J, Canal I, Barbas JA, Ferrús A (1993) Frequenin: a novel calcium binding protein that modulates synaptic efficacy in the Drosophila nervous system. Neuron 11:15-28.

Pumplin DW, Reese TS, Llinas R (1981) Are the presynaptic active zone particles the calcium channels? Proc Natl Acad Sci USA 78:7210-7213.

Quigley PA, Mercier AJ (1997) Modulation of crayfish superficial extensor muscles by a FMRFamide-related neuropeptide. Comp Biochem Physiol 118A:1313-1320.

Quigley PA, Msghina M, Govind CK, Atwood HL (1999) Visible evidence for differences in synaptic effectiveness with activity-dependent vesicular uptake and release of FM1-43. J Neurophysiol 81:356-370.

Rash JE, Walrond JP, Morita M (1988) Structural and functional correlates of synaptic transmission in the vertebrate neuromuscular junction. J Electron Microsc Tech 10:153-185.

Ravin R, Spira ME, Parnas H, Parnas I (1997) Simultaneous measurement of intracellular $\mathrm{Ca}^{2+}$ and asynchronous transmitter release from the same crayfish bouton. J Physiol (Lond) 501.2:251-262.

Redman RS, Searl TJ, Hirsch JK, Silinsky EM (1997) Opposing effects of phorbol esters on transmitter release and calcium currents at frog motor nerve endings. J Physiol (Lond) 501.1:41-48.

Rheuben MB (1985) Quantitative comparison of the structural features of slow and fast neuromuscular junctions in Manduca. J Neurosci 5:1704-1716.

Rheuben MB, Kammer AE (1983) Mechanisms influencing the amplitude and time course of the excitatory junction potential. In: The physiology of excitable cells, pp 393-409. New York: Alan R. Liss.

Rheuben MB, Reese TS (1978) Three-dimensional structure and membrane specializations of moth excitatory neuromuscular synapse. J Ultrastruct Res 65:95-111.

Rivosecchi R, Pongs O, Theil T, Mallart A (1994) Implication of frequenin in the facilitation of transmitter release in Drosophila. J Physiol (Lond) 474:223-232.

Roberts WM, Jacobs RA, Hudspeth AJ (1990) Colocalization of ion channels involved in frequency selectivity and synaptic transmission at presynaptic active zones of hair cells. J Neurosci 10:3664-3684.
Sabatini BL, Regehr WG (1997) Control of neurotransmitter release by presynaptic waveform at the granule cell to Purkinje cell synapse. J Neurosci 17:3425-3435.

Schikorski T, Stevens CF (1997) Quantitative ultrastructural analysis of hippocampal excitatory synapses. J Neurosci 17:5858-5867.

Stanley EF (1997) The calcium channel and the organization of the presynaptic transmitter release face. Trends Neurosci 20:404-409.

Stern MD (1992) Buffering of calcium in the vicinity of a channel pore. Cell Calcium 13:183-192.

Stevens CF, Wang Y (1995) Facilitation and depression at single central synapses. Neuron 14:795-802.

Südhof TC (1995) The synaptic vesicle cycle: a cascade of proteinprotein interactions. Nature 375:645-653.

Tang YG, Zucker RS (1997) Mitochondrial involvement in post-tetanic potentiation of synaptic transmission. Neuron 18:483-491.

Tank DW, Regehr WG, Delaney KR (1995) A quantitative analysis of presynaptic calcium dynamics that contribute to short-term enhancement. J Neurosci 15:7940-7952.

Walmsley B, Alvarez FJ, Fyffe REW (1998) Diversity of structure and function at mammalian central synapses. Trends Neurosci 21:81-88.

Walrond JP, Reese TS (1985) Structure of axon terminals and active zones at synapses on lizard twitch and tonic muscle fibers. J Neurosci 5:1118-1131.

Walrond JP, Govind CK, Heustis S (1993) Two structural adaptations for regulating transmitter release at lobster neuromuscular synapses. J Neurosci 13:4831-4845.

Wernig A, Carmody JJ, Anzil AP, Hansert E, Marciniak M, Zucker H (1984) Persistence of nerve sprouting with features of synapse remodelling in soleus muscles of adult mice. Neuroscience 11:241-253.

Wojtowicz JM, Smith BR, Atwood HL (1991) Activity-dependent recruitment of silent synapses. Ann NY Acad Sci 627:169-179.

Wojtowicz JM, Marin L, Atwood HL (1994) Activity-induced changes in synaptic release sites at the crayfish neuromuscular junction. J Neurosci 14:3688-3702.

Zucker RS (1996) Exocytosis: a molecular and physiological perspective. Neuron 17:1049-1055.

Zucker RS, Lara-Estrella LO (1983) Post-tetanic decay of evoked and spontaneous transmitter release and a residual-calcium model for synaptic facilitation at crayfish neuromuscular junctions. J Gen Physiol 81:355-372. 